\title{
Evaluation of surfactant flooding using interwell tracer analysis
}

\author{
Rasoul Khaledialidusti $^{1} \cdot$ Jon Kleppe $^{1} \cdot$ Saeid Enayatpour $^{2}$
}

Received: 2 October 2015/Accepted: 9 October 2016/Published online: 26 October 2016

(C) The Author(s) 2016. This article is published with open access at Springerlink.com

\begin{abstract}
Surfactant flooding is an important enhanced oil recovery (EOR) method, especially in carbonate oil reservoirs where water flooding may not have an effect on oil recovery as much as for sandstone reservoirs. This is because of the initial wettability of most carbonate reservoirs that is mixed- or oil-wet. Since surfactant flooding has a great impact on both fluid-fluid and rock-fluid interactions, it can be an efficient EOR method for these kinds of reservoirs. Surfactants affect fluid-fluid interactions by reducing interfacial tension (IFT) between water and oil phases and rock-fluid interactions by wettability alteration. The objective of this paper is the evaluation of these two surfactant mechanisms in non-fractured carbonate reservoirs using UTCHEM, the University of Texas chemical compositional simulator. In this paper, first, the laboratory data of two surfactant spontaneous imbibition tests for carbonate cores are successfully matched with modeled data to evaluate the mechanisms of surfactant flooding. Second, the field-scale surfactant flooding is simulated using the experimental data from spontaneous imbibition tests. Several cases are modeled in order to study the effect of surfactant flooding in terms of decreasing IFT and wettability alteration. Since the formation brine salinity in most reservoirs is more than the
\end{abstract}

Rasoul Khaledialidusti

rasoul.khaledialidusti@ntnu.no

Jon Kleppe

jon.kleppe@ntnu.no

Saeid Enayatpour

s.e@utexas.edu

1 Norwegian University of Science and Technology, Trondheim, Norway

2 University of Texas at Austin, Austin, USA optimum salinity of surfactant phase behavior, the benefit of combining surfactant and low-salinity water is also investigated. Finally, tracer test simulation is performed to estimate the average oil saturation within the swept pore volume at the end of each recovery mode.

Keywords Surfactant flooding - Interfacial tension . Wettability alteration - Interwell tracer method

\section{Introduction}

It is widely accepted that in petroleum reservoirs only a small fraction of the original oil-in-place is economically recoverable by primary recovery methods via natural forces and secondary recovery via waterflooding. As a result, a significant amount of oil ends up unrecovered in porous media which results in an oil recovery factor typically less than 50\% (Teklu et al. 2013). This barrier is even more significant in carbonate reservoirs compared to sandstone reservoirs because of the wettability of carbonate rock which is more mixed- or oil-wet. The residual oil saturation $\left(S_{\text {or }}\right)$ varies depending on lithology, pore size distribution, permeability, wettability, fluid characteristics, recovery method, and production scheme. In order to produce the unrecovered oil after waterflooding, EOR methods have been a popular industry approach in order to decrease $S_{\text {or }}$. Since the main mechanisms of all EOR methods are directly related to fluid-fluid and fluid-rock interactions, the effects of these two concepts in $S_{\text {or }}$ reduction are investigated as follows:

\section{Fluid-fluid interactions}

This type of interactions in porous media is governed by the interplay between capillary, viscous and gravitational forces. Oil trapping during immiscible displacement in 
porous media is mainly because of the capillary forces. The trapped oil can be recovered if the amount of viscous or gravity forces acting on the trapped oil exceeds the capillary forces. The relative contribution of gravity and capillary forces on $S_{\text {or }}$ is determined by the bond number $\left(N_{\mathrm{B}}\right)$, which is a dimensionless number representing the ratio of gravity to capillary forces (Du Prey 1978). The relative contribution of viscous forces and capillary forces on $S_{\text {or }}$ is determined by the capillary number $\left(N_{\mathrm{C}}\right)$, which is a dimensionless number that determines the relative contribution of viscous and capillary forces (Taber 1969; Stegemeier 1977, Lake 1989). A number of different mathematical relations between $N_{\mathrm{B}}$ and $N_{\mathrm{C}}$ have been proposed by various researchers (Cense and Berg 2009).

These two dimensionless numbers were combined by Jin (1995) into a total trapping number $\left(N_{\mathrm{T}}\right)$ to examine residual mobilization in an arbitrary flow regime having both horizontal and vertical components of flow. $N_{\mathrm{T}}$ is also used to correlate changes in the residual phase saturations during immiscible displacement and is graphically represented as capillary desaturation curve (CDC). It is generally accepted that $S_{\text {or }}$ decreases by increasing $N_{\mathrm{T}}$ (Lake 1989). $N_{\mathrm{T}}$ can be increased in three ways:

1. Increasing the injection fluid velocity: The injection fluid velocity is limited by pump capacity and the formation injectivity.

2. Increasing the displacing fluid viscosity: Injecting polymer solution into reservoirs is an applicable technique in order to increase fluid viscosity; however, the injection of high amount of polymer is also limited, at least by economics.

3. Reducing IFT between water and oil: This is another applicable way in order to reduce the amount of $S_{\text {or }}$. There are some strategies in order to reduce IFT such as surfactant flooding.

\section{Rock-fluid interactions}

There is also another way to decrease $S_{\text {or }}$ which is related to the rock-fluid interaction and wettability of the formation rock. The wettability of many carbonate reservoirs is mixed- or oil-wet with low rock permeability. Since the capillary driving force is more effective in water-wet rocks and high rock permeability, this driving force is very weak and oil recovery is less in carbonate reservoirs after waterflooding. Therefore, changing the wettability of carbonate reservoir is inevitable in order to improve the oil recovery. Changing the wettability can be improved toward more water-wet in such cases by using chemicals such as surfactants and alkali (Lake 1989; Khaledialidusti et al. 2015c) or heat (Al-Hadhrami and Blunt 2000).

Since surfactant flooding has the capability of improving both fluid-fluid interactions by reducing IFT and rock-fluid interactions by changing the wettability toward more water-wet, it can be one of the most efficient EOR methods especially for carbonate reservoirs (Hirasaki 1981; Delshad et al. 1986). To understand the effect of surfactant in order to increase overall oil recovery, these two mechanisms are reviewed in the following

\section{Surfactant mechanisms: phase behavior for ultra-low IFT}

The main mechanism of surfactant is related to reduction in the surface energy and IFT. Surfactant phase behavior has a great impact on the amount of IFT reduction. There are some parameters such as surfactant type and concentration, brine salinity, oil chain length, temperature, and pressure which play a significant role in surfactant phase behavior. All of these parameters are described briefly as follows:

1. Surfactant type and concentration: Four groups of surfactants based on the polar portion are: anionics, cationics, nonionics, and amphoteric (Lake 1989). Nonionic surfactants do not have any charge. A positively charged rock will strongly attract an anionic surfactant, and a negatively charged rock will strongly attract a cationic surfactant. Amphoterics surfactants exhibit properties of two or more groups of other surfactant groups and have not been used in chemical EOR. As a result, applying a suitable surfactant completely depends on the rock mineralogy under the reservoir condition. Cationic surfactants, for example, have not been widely used in the reservoirs including high amount of clay because they are easily adsorbed by negatively charged surface of interstitial clays. Among these types, anionic surfactants are widely used in EOR due to their lower adsorption on reservoir rocks as compared to other types of surfactants. It should be noted that some factors such as surface charge, brine salinity, and crude oil components are important to choose a suitable surfactant in different reservoirs.

Micelles and Critical Micelle Concentration (CMC): Carale et al. (1994) introduced the concept of CMC. It occurs when surfactant molecules reach a certain "critical" concentration in brine. IFT of oil-brine becomes constant above the CMC because the additional surfactant forms additional micelles. Beyond this critical concentration, IFT increases. Karnanda et al. (2012) investigated the effect of three surfactants in various concentrations. The results showed that IFT declines sharply with the increase in surfactant concentration. After a certain concentration, the drop becomes very slight, and this inflection point is referred to as CMC, known to be the economical concentration for surfactant flooding. The trend seen in their work 
agrees well with that obtained by previous investigators (Shah and Schechter 1977; Santos et al. 2009).

2. Salt concentration: Strong dependency between IFT and brine salinity has been shown that at a critical salt concentration, IFT reaches the minimum value (Lake 1989). By changing the salinity of brine, the partition coefficient of the surfactant between oil and brine alters. This alteration affects the amount of IFT. The lowest IFT happens at optimal salinity when the most portion of the surfactant is at oil-water interface. The tendency of most surfactants for staying in brine is more in low-salinity water. On the other hand, with increasing the salinity of brine, the tendency of surfactant to trap in the oleic phase increases; therefore, very little of it partitions into the interface or aqueous phase.

3. Oil chain length: The optimal salinity and partitioning of surfactant in oil and brine phase are considerably related to oil properties. Gale and Sandvik (1973) have showed that crude oils with high aromatic hydrogen content produce lower IFT compared to crude oils with lower aromatic hydrogen content.

4. Temperature: Karnanda et al. (2012) have investigated the effect of temperature on IFT. The results indicated minor temperature effect on IFT measurements with brine solution, purified water, and anionic surfactants; however, the significant effects were seen for solutions of nonionic surfactants. It can be concluded that there is not a general treatment for the temperature effect on IFT and it is quite a complex phenomenon which many other factors specially the type of surfactants can affect it.

5. Pressure: Karnanda et al. (2012) have also studied the effect of pressures on IFT. No effect was seen for pressure variations, except for pure brine where minimal increase on IFT was seen. It can be concluded that IFT is weakly dependent on pressure.

Surfactant phase behavior considers up to five volumetric components (oil, water, surfactant, and up to two alcohols) which form three pseudo-components in a solution. In the absence of alcohols, only the three other components are considered. The concept of surfactant/oil/ brine phase behavior is evaluated by a ternary diagram, and usually the surfactant pseudo-component is placed at the top apex, brine at the lower left, and oil at the lower right (Winsor 1954; Healy and Reed 1974, 1977; Healy et al. 1976; Nelson and Pope 1978; Lake 1989). Surfactants typically exhibit proper aqueous-phase solubility and poor oil-phase solubility at low brine salinities. This concept leads to the fact that at low brine salinities, an overall composition in the two-phase region will split into two phases: an excess oil phase and a water external microemulsion phase. This system is known as a lower phase microemulsion, Winsor Type II(-).

At high brine salinities, surfactant solubility in the aqueous phase is sharply reduced. For this reason, at high brine salinity, an overall composition in the two-phase region will split into an oil external microemulsion phase and an excess brine phase. This system is known as an upper phase microemulsion, Winsor Type II $(+)$.

In addition to the two extremes discussed above, there is a third type of phase behavior which is referred to as the brine salinities between low and high brine salinities, also known as intermediate salinity. In this type, all three phases of brine, microemulsion, and oil coexist. This system is known as a middle phase microemulsion, Winsor type III.

The "solubilization parameters" and the IFTs between the microemulsion/excess oil and microemulsion/excess brine are correlated by Healy and Reed (1974) and Huh (1979). The solubilization parameters are ratio of oil/surfactant $\left(V_{\mathrm{o}} / V_{\mathrm{s}}\right)$ or water/surfactant $\left(V_{\mathrm{w}} / V_{\mathrm{s}}\right)$ by volume (Fig. 1). The experimental data have been taken from Levitt et al. (2009), and solid lines are simulated data. The salinity at the crossover point of these two interfacial tensions is called "optimum salinity" and is the salinity at which the microemulsion solubilizes equal amounts of oil and water. The salient fact is that the IFT of the whole system is minimized at the optimum salinity Levitt et al. (2009).

Brine salinity and divalent cation have a considerable effect on the phase behavior. The equivalent alkane carbon number of the oil or solvent and changes in temperature or pressure also cause a phase environment shift from one type to another type. The optimum salinity decreases as the

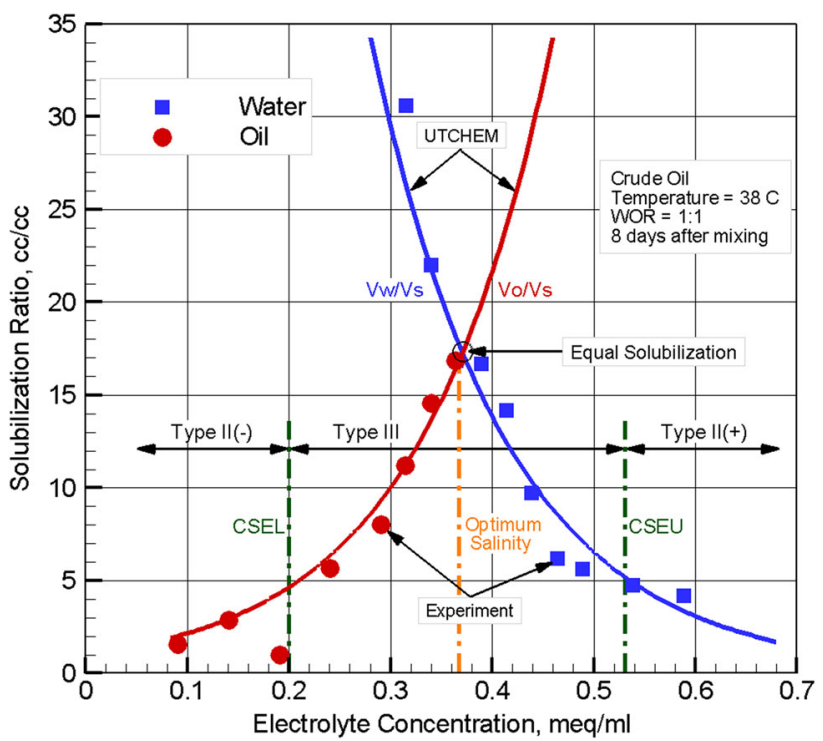

Fig. 1 Surfactant phase behavior-solubilization plot $\left(V_{\mathrm{o}} / V_{\mathrm{s}}\right.$ and $V_{\mathrm{w}} /$ $V_{\mathrm{s}}$ ) as a function of salinity 
temperature increases for anionic surfactants and increases as the temperature increases for nonionic surfactants (Bourrel and Schechter 1988). The presence of alcohols also can affect the phase boundaries (Dwarakanath et al. 2008).

While the optimum salinity with sodium chloride is relatively constant, reservoir brines including divalent cations such as calcium and magnesium bring about complications. In reservoir brine including divalent cations, the optimum salinity is a function of surfactant concentration and ratio of divalent to sodium ions and it decreases to low values at low surfactant concentrations (Hirasaki 1982; Hirasaki et al. 1983)

The salinities at which the three equilibrium phases form or disappear are called lower and upper limits of effective salinity $\left(C_{\mathrm{SEL}}\right.$ and $\left.C_{\mathrm{SEU}}\right)$, and optimum salinity is the mean of these two limits. The divalent ions among the electrolyte brine composition play a strong role in ion exchange from the clays to the flowing phases, and this ion exchange affects the effective salinity (Hill et al. 1977; Pope et al. 1978; Hirasaki et al. 2011). Since the microemulsion droplets have a great affinity for divalent ions, they act as a flowing ion exchange medium (Hirasaki 1982; Hirasaki and Lawson 1986). The amount of clay in carbonate rocks is less than sandstones, so the exchange of divalent ions is weaker in carbonates.

Since many reservoirs contain high-salinity brine, surfactant flooding leads to unsatisfactory and uneconomical results. This is because of the fact that displacement of residual oil by surfactant flooding requires reducing the IFT to ultra-low values to mobilize the disconnected oil droplets. Therefore, there are some approaches on how ultra-low IFT can be achieved in order to enhance oil recovery:

1. Performing a soft water preflush (Gupta and Trushenski 1979): The purpose of the preflush is to displace high-salinity brine away and to reduce the formation salinity to a value near optimum salinity. This approach causes a problem because soft water preflush leads to increasing the contact of the viscous surfactant slug with the formation rock which was bypassed by the preflush (Hirasaki et al. 2011).

2. Performing salinity gradient (Nelson 1981; Hirasaki et al. 1983): The purpose of this approach is creating salinity over the optimum salinity ahead and under the optimum salinity behind the active region where the surfactant has more concentration. In this approach, the effective salinity profile is around the optimum salinity in the active region.

3. Designing the new surfactant formulation (Maerker and Gale 1992; Flaaten et al. 2009): The purpose of designing new formulation is to change the optimum salinity of the surfactant to near the formation salinity. In this approach, there is no need for soft water in order to reach the ultra-low IFT and in consequence the problem of the soft water preflush approach is ignored due to constant salinity.

4. Another approach in order to create optimum condition is to add alcohol to increase the optimum salinity of the formation.

It should be noted that performing salinity gradient may be modified based on the reservoir conditions. If the reservoir salinity is lower than optimum salinity for surfactant phase behavior, a preflush may be necessary to increase the salinity of the brine ahead of the surfactant slug. Or else, if the reservoir salinity is higher than optimum salinity of surfactant phase behavior, a preflush may be necessary to decrease the salinity of the brine ahead of the surfactant slug.

\section{Surfactant mechanisms: wettability alteration}

Another mechanism of surfactant flooding is related to the wettability alteration. Under the right conditions, the surfactant adsorbs on the rock surface and preferentially attracts a particular phase. This, in turn, changes the wettability of the rock. It is generally accepted that wettability in sandstones and carbonates is quite different. This difference in sandstones and carbonates is mainly because of the different surface electrical charge in these two types of reservoir rocks, which leads to different behavior of surfactant adsorption (Treiber and Owens 1972; Anderson 1986a, b; Menezes et al. 1989). The surface charge of the formation rock has a key role on the surfactant adsorption which is a strong function of the $\mathrm{pH}$, so the adsorption of the most commonly used anionic surfactants typically decreases with an increase in $\mathrm{pH}$.

Dubey and Doe (1993) showed that at reservoir $\mathrm{pH}$ conditions, silica and clay surfaces as well as crude oil include negative electrical charge. At neutral $\mathrm{pH}$, clays have a negative charge on the faces and a positive charge at the edges. The edges exhibit $\mathrm{pH}$-dependent charge characteristics and thus are expected to reverse their charge at a pH of about nine (Hirasaki et al. 2011). Menezes et al. (1989) and Anderson (1986a, b) investigated that there is a low amount of clay in carbonates in comparison with sandstones and this amount is sufficiently small to be ignored and they observed that carbonate surfaces are positively charged at basic conditions of $\mathrm{pH}<9.5$. For this reason, carbonates have a considerable tendency to adsorb negatively charged oil particles (e.g., acidic groups) by electrostatic attraction. Hence, the carbonates are expected to be mixed- to oil-wet. Since the primary mechanism for the adsorption of anionic surfactants on sandstone and 
carbonate formation is the ionic attraction between positively charged mineral sites and the negative surfactant anion (Zhang et al. 2006), the surface charge of carbonates also leads to adsorption of anionic surfactant more easily as well.

Contrary to carbonate rocks, there is a high amount of clay and silica in sandstone rocks. Since silica is negatively charged at reservoir conditions, sandstones are in general negatively charged at $\mathrm{pH}>2$ and exhibit negligible adsorption of anionic surfactants (Buckley et al. 1989; Hirasaki et al. 2011). It can be concluded that the mechanism of the wettability modification of carbonate surfaces is quite different from that of sandstones. The effect of surface charged on the wettability and $S_{\text {or }}$ is compared in Table 1.

In this paper, in order to understand the effects of surfactant on wettability alteration, the alkaline/surfactant imbibition laboratory results conducted at Rice University (Hirasaki et al. 2004) are modeled using UTCHEM. Next, we have extended our work to field-scale simulations to study the effect of IFT reduction and wettability alteration mechanisms. The benefits of combining surfactant with low-salinity water are also studied in order to get the ultralow IFT.

\section{Imbibition cell test}

Some imbibition cell tests using reservoir cores of carbonate dolomite formation from the Yates oil field with moderate porosity and low permeability were performed in order to study the effect of candidate surfactant on oil recovery (Hirasaki et al. 2004). The formation brine in the experiment contained mostly $\mathrm{NaCl}$ and small concentrations of $\mathrm{CaCl}_{2}$ and $\mathrm{MgCl}_{2}$. In this study, the results from two of these experiments are used to investigate the effect of each mechanisms of surfactant on this carbonate rock. The first sample is Core $\mathrm{C}$ which was saturated but not aged by crude oil before imbibition tests. The second sample is Core B which contrary to the former core was aged in the crude oil at $80{ }^{\circ} \mathrm{C}$ before the imbibition test.

The first experiments were conducted using formation brine, and negligible amounts of oil were recovered after just one week. It can be inferred that this insignificant amount of oil recovery is a result of the wettability of the dolomite cores where the cores were anticipated to be mixed- or oil-wet. For this reason, the second experiments were conducted using an alkali/surfactant solution. In this experiment, $0.3 \mathrm{M}$ sodium carbonate $\left(\mathrm{Na}_{2} \mathrm{Co}_{3}\right)$ as alkali solution was also added to the aqueous solution in order to reduce the surfactant adsorption and also to generate in situ surfactants (soap) as a result of reacting with the naphthenic acids in the Yates crude oil (Hirasaki et al. 2004). In the second experiments, considerable amount of spontaneous imbibition was recorded when the brine was replaced by the alkaline/surfactant solution. The cores and fluid properties and experiments results are listed in Table 2.

This procedure was also performed using Core B which was aged. Insignificant amounts of oil were recovered using formation brine in this core just as for Core $\mathrm{C}$, which is not aged. Then, the test was repeated for Core B using alkali/surfactant solution with exactly the same conditions of the previous experiments using Core $\mathrm{C}$. In this test using Core $\mathrm{B}$, more oil is recovered in comparison with Core $\mathrm{C}$. More details of these imbibition tests are reported by Hirasaki et al. (2004).

Based on a comparison of the results of oil recovery using alkali/surfactant solution in both cores $(14 \%$ for Core C and $44 \%$ for Core B), it can be inferred that the wettability of Core B was altered to more oil-wet during the aging process and then altered back to a mixed- or water-wet state during the surfactant imbibition cell test. On the other hand, Core $\mathrm{C}$ was not aged and was either not altered or altered to a lesser extent during the surfactant imbibition test. However, the permeability and initial water saturation of Core B are higher than Core C, but the difference in oil recovery is considered more significant than would be caused by small variations in permeability and initial water saturation. Therefore, the wettability alteration is considered the real reason for more oil recovery during the tests.

The reason of matching Core $\mathrm{C}$ is to obtain rock and fluid properties, while the purpose of matching Core B was to get rock properties with respect to wettability alteration effects.

A 3D numerical model using homogeneous Cartesian grid including fluid gridblocks ("non-rock") and rock

Table 1 Effect of surface charge on wettability

\begin{tabular}{lllll}
\hline Formation type & Amount of clay and silica & Surface charge & Wettability & Anionic surfactant adsorption \\
\hline Sandstone & High & Negative at $\mathrm{pH}>2$ & Mixed- to water-wet & Low \\
Carbonate & Low & Positive at $\mathrm{pH}<9.5$ & Mixed- to oil-wet & High \\
\hline
\end{tabular}

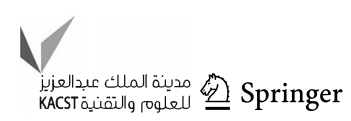


Table 2 Core properties: imbibition experiment

\begin{tabular}{ll}
\hline & Core C/Core B \\
\hline Diameter (ft) & 0.125 \\
Length (in.) & 0.25 \\
Porosity (\%) & 24 \\
Permeability (md) & $40 / 122$ \\
Brine & $5.815 \mathrm{~g} / 1 \mathrm{NaCl}$, \\
Crude oil & $30^{\circ} \mathrm{API}(0.88 \mathrm{~g} / \mathrm{cc}), 19 \mathrm{cp}$ \\
Pressure drop (psi) & 130 \\
Initial water saturation & $0.18 / 0.32$ \\
Aging & $-/ 80{ }^{\circ} \mathrm{C} 24 \mathrm{~h}$ \\
Time in brine (days) & $-/ 14$ \\
Recovery in brine (\% OOIP) & $-/ 0$ \\
Surfactant & $\mathrm{cs}-330+\mathrm{TDA}-4 \mathrm{PO}$ \\
Surfactant concentration (wt $\%)_{\text {Na }} \mathrm{CO}_{3}$ (M) & $0.025+0.025$ \\
Time in surfactant (days) & 0.3 \\
Recovery in surfactant $(\%$ OOIP) & 138 \\
Remaining oil saturation & $14 / 44$ \\
\hline
\end{tabular}

gridblocks is set up to simulate both the core and surrounding fluid in the imbibition cell experiment by UTCHEM. The grid model is developed using $8 \times 8 \times 8$ gridblocks and is intended to simulate both the imbibition cell and the core to simulate fluid flowing from the open imbibition cell into the rock and expelling oil to the top. A vertical cross section through the center of the model is shown in Fig. 2. The middle of the grid $(6 \times 6 \times 6)$ is for simulating petrophysical properties representing the rock, and the remaining gridblocks are for simulating properties representing the imbibition cell. The non-rock gridblocks are located at the top and on the sides of the grid. The oil saturation and the surfactant concentration for the imbibition simulation of Core B are shown in Fig. 2 at initial condition and after 10 days. The blue and the red regions initially represent zero initial surfactant concentration in the rock gridblocks and $0.05 \%$ initial surfactant concentration in the non-rock gridblocks, respectively. All other properties of the simulation are given in Tables 3 and 4 . Since a 1D mathematical model has been performed, the flow only imbibes vertically.

Simulation of the imbibition cell test is complicated due to the following reasons: Since there are no wells to cause flow, the convective fluxes are very small and lead to severe variation in properties between rock and non-rock gridblocks. Therefore, considering mechanisms such as molecular diffusion becomes important. Several other simulation input parameters such as time steps size, grid orientation, and initial properties also have considerable effects on the final result. The rate of formation of microemulsion also has a great impact on the final results which are determined by surfactant molecular diffusion and CMC. The ability of the surfactant to reduce the capillary forces and mobilize oil is the other mechanism which should be modeled by the surfactant phase behavior and capillary desaturation. In order to reduce the surfactant adsorption, some sodium carbonate was added in the spontaneous experiment. Therefore, the surfactant adsorption is ignored in the simulations. The next assumption is physical dispersion. According to the nature of spontaneous imbibition, low velocities are expected. Therefore, this parameter is assumed to be negligible and is ignored in the spontaneous simulations.
Fig. 2 Oil saturation (left), surfactant concentration (right): Case B
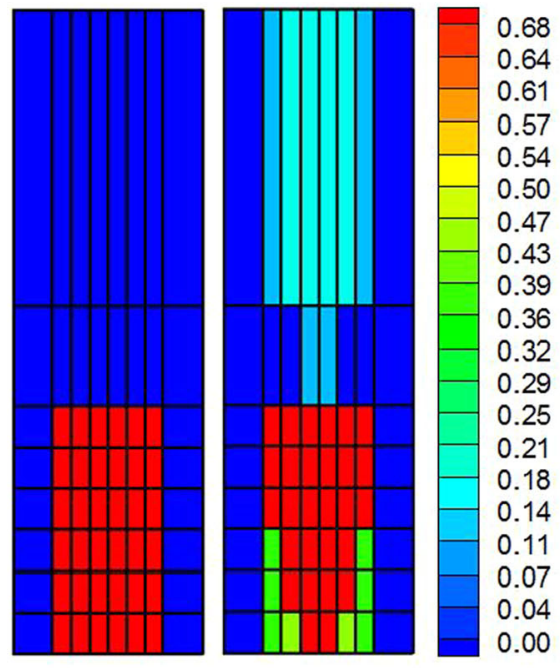

Time $=0$, Time $=10$ (days)
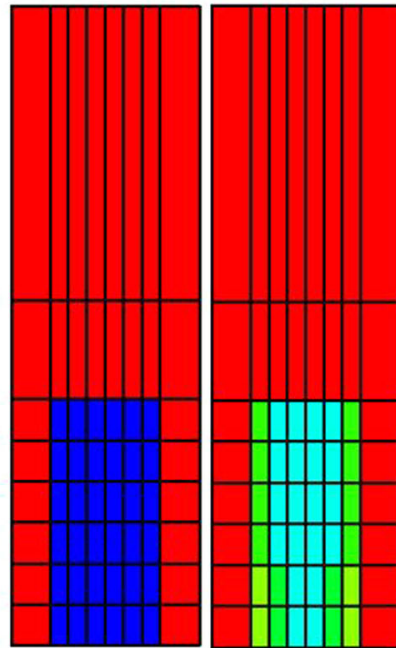

$5.0 \mathrm{E}-04$

4.6E-04

4. $2 \mathrm{E}-04$

$3.8 \mathrm{E}-04$

$3.4 \mathrm{E}-04$

3.0E-04

2.6E-04

$2.2 \mathrm{E}-04$

$1.8 \mathrm{E}-04$

1. $4 \mathrm{E}-04$

$1.0 \mathrm{E}-04$ 
Table 3 Rock and non-rock properties: simulation

\begin{tabular}{lll}
\hline & Rock properties & $\begin{array}{l}\text { Non-rock } \\
\text { properties }\end{array}$ \\
\hline & Core C/Core B & \\
Porosity (\%) & 24 & 1 \\
Permeability (md) & $40 / 122$ & 10,000 \\
Initial water saturation & $0.18 / 0.32$ & 1 \\
Salinity (meq/ml) & 0.3 & 0.3 \\
Residual water saturation & $0.18 / 0.32$ & 0.0001 \\
Residual oil saturation & $0.7 / 0.38$ & 0.0001 \\
Water endpoint relative permeability & 0.23 & 1 \\
Oil endpoint relative permeability & 0.59 & 1 \\
Water relative permeability exponent & 2.9 & 1 \\
Oil relative permeability exponent & 3.3 & 1 \\
Capillary pressure endpoint (CPC) & $3 /(-3,3)$ & 0 \\
Capillary pressure exponent (EPC) & 2 & 0 \\
\hline
\end{tabular}

Determining the surfactant parameters (microemulsion viscosity, IFT, surfactant adsorption, and microemulsion phase behavior) is important for UTCHEM and requires precise curve fitting of the experimental data. In our simulations and in the spontaneous imbibition tests, the experimental evaluations that were performed by Levitt et al. (2009) are used. They examined some surfactants in order to determine the optimum salinity and corresponding IFT, solubilization ratio, as well as the compatibility with this reservoir's rock type, temperature, synthetic formation brine, and crude oil. Microemulsion phase behavior is matched with the laboratory solubilization ratio for several salinities as is shown in Fig. 1. The important information obtained from this plot is optimum salinity for this surfactant/crude oil/brine solution which was relatively high $(0.365 \mathrm{meq} / \mathrm{ml})$, solubilization ratio at optimum salinity (16.8), and fluid concentration (1\% surfactant). By knowing the solubilization ratio and using the fact that optimum salinity is the average of $C_{\mathrm{SEL}}$ and $C_{\mathrm{SEU}}$, these two parameters are obtained by trial and error procedures (Table 5). Using the Huh (1979) correlation and the solubilization ratio at optimum salinity, an approximate IFT value of almost $0.001 \mathrm{dyne} / \mathrm{cm}$ is expected.
Initial simulations of both Core $\mathrm{C}$ and Core $\mathrm{B}$ are run to determine the oil recovery based on the constant wettability assumption during surfactant imbibition test. The relative permeability and capillary pressure parameters are set up to be mixed-wet toward oil-wet (Fig. 3). This is because there was a negligible oil recovery via water spontaneous imbibition in the laboratory. Since Core $\mathrm{C}$ is not aged, this assumption can be satisfying to match the final result of oil recovery. On the other hand, this assumption cannot be enough to match the final result of oil recovery in Core B because this case is aged which causes (1) the wettability become more oil-wet initially and (2) surfactant imbibition test led to alteration in wettability. So, it is necessary to manipulate parameters such as relative permeability, and capillary pressure, and capillary desaturation parameters in order to match the final result of Core B.

Core $\mathrm{C}$ is simulated with the mentioned conditions and sensitivity analysis of assumed parameters such as relative permeability, capillary pressure, surfactant diffusion, CMC, IFT, residual oil saturation, and heterogeneity to understand more accurately the transport mechanisms which affected the test. We have attempted to match the modeled result with the experimental one in order to extract all unknown petrophysical and chemical parameters regarding wettability and IFT reduction, respectively. The relative permeability and capillary pressure in mixed-wet rocks are shown in Fig. 3 where red color is considered to get the best match in oil recovery (Fig. 4).

Matching modeled results with experimental results is more complicated in Case B. This case, first, is simulated with unknown petrophysical and chemical parameters which are obtained in the simulation of Core $\mathrm{C}$. The result of the simulation showed that getting a realistic match with experimental result was impossible. The reason is that the wettability in this case has been considerably altered during surfactant spontaneous imbibition. Since petrophysical parameters such as relative permeability, capillary pressure, and capillary desaturation parameters are dependent on wettability, the alteration of these parameters is inevitable. Secondly, these parameters are modified toward a more water-wet condition as shown in Fig. 3 via blue color. The simulation with water-wet conditions showed a

Table 4 Model description

\begin{tabular}{llcc}
\hline & Imbibition & \multirow{2}{*}{ Reservoir } \\
\cline { 2 - 3 } & Total & Rock & \\
\hline Number of gridblocks & $8 \times 8 \times 8$ & $6 \times 6 \times 6$ & $15 \times 15 \times 20$ \\
Dimension & $0.191 \mathrm{ft} \times 0.191$ & $0.111 \mathrm{ft} \times 0.111$ & $750 \mathrm{ft} \times 750$ \\
& $\quad \mathrm{ft} \times 0.65 \mathrm{ft}$ & $\mathrm{ft} \times 0.25 \mathrm{ft}$ & $\mathrm{ft} \times 99.1 \mathrm{ft}$ \\
$K_{\mathrm{v}} / K_{\mathrm{h}}$ & 1 & & 0.05 \\
Depth $(\mathrm{ft})$ & 0.35 & & 4700 \\
\hline
\end{tabular}


Table 5 Fluid properties

\begin{tabular}{ll}
\hline Water & $1 \mathrm{~g} / \mathrm{cc}, 0.72 \mathrm{cp}$ \\
\hline Oil & $30^{\circ} \mathrm{API}(0.87 \mathrm{~g} / \mathrm{ml}), 5 \mathrm{cp}$ \\
Initial reservoir brine salinity $(\mathrm{meq} / \mathrm{ml})$ & $1(\mathrm{NaCl})$ \\
Lower salinity limit $\left(C_{\mathrm{SEL}}\right)(\mathrm{meq} / \mathrm{ml})$ & 0.2 \\
Upper salinity limit $\left(C_{\mathrm{SEU}}\right)(\mathrm{meq} / \mathrm{ml})$ & 0.53 \\
Intercept at zero salinity & 0.035 \\
Intercept at optimum salinity & 0.0288 \\
Intercept at twice optimum salinity & 0.056 \\
\hline
\end{tabular}

faster response to oil production and a higher cumulative oil recovery. This was due to the increase in oil relative permeability and initial change in capillary pressure from negative to positive. Therefore, more surfactant solution imbibed into the rock gridblocks and displaced more oil before decreasing the capillary pressure to zero due to IFT reduction. The matching simulation result of oil recovery with the experiment result was not achieved. Finally, the petrophysical parameters are to an acceptable extent interpolated in between to get the best match as shown in Fig. 3 via green color because of the fact that the process of wettability alteration is a gradual, not a sudden mechanism. The final matching of oil recovery is shown in Fig. 4.

\section{Upscaled simulations}

In this section, the effect of surfactant mechanisms (IFT reduction and wettability alteration) on the oil recovery in a mixed-wet dolomite formation with almost high-salinity formation brine $1(\mathrm{meq} / \mathrm{ml})$ is investigated. Since the

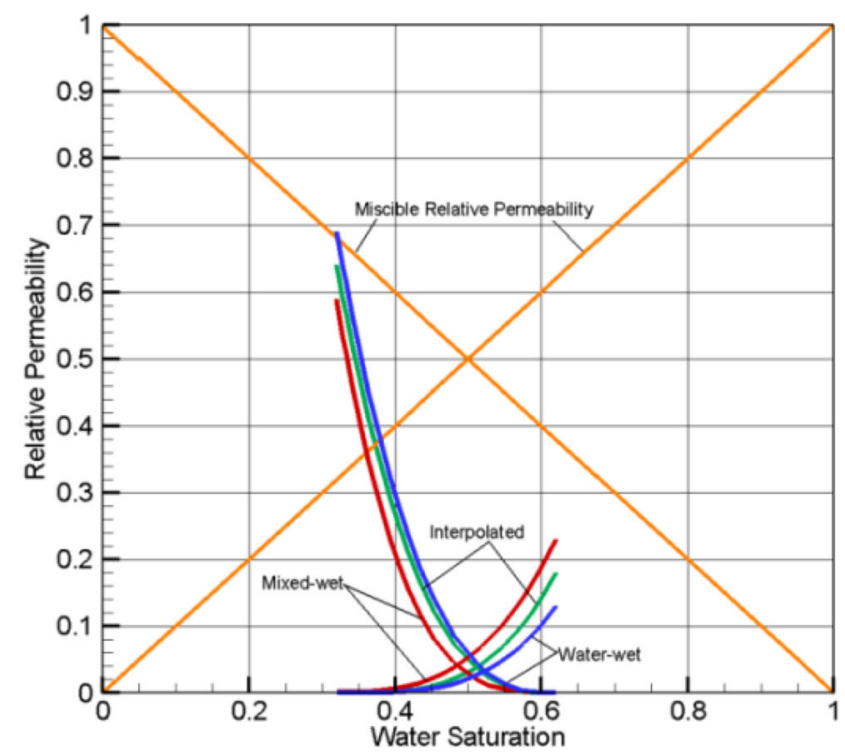

Fig. 3 Relative permeability (left) and capillary pressure (right) curves formation brine salinity is more than the optimum salinity of the candidate surfactant phase behavior (Fig. 1), combining surfactant with low-salinity water is one of the most efficient approaches in order to reach the ultra-low IFT. In order to study the effect of low-salinity water on the phase behavior of surfactant and also the benefit of combining surfactant with low-salinity water, several 3D simulations are performed using UTCHEM with the petrophysical parameters which are obtained via the simulations of imbibition tests in the previous section and some other parameters which are provided by field operator as shown in Table 5 and Table 6.

A heterogeneous model is used to investigate the effect of low-salinity water on the phase behavior of surfactant and also the benefit of combining surfactant with lowsalinity water. Since the reservoir rocks are heterogeneous in terms of mineral composition, a stochastic distribution of permeability in a range between 50 and $200 \mathrm{md}$ for each gridblock is selected in order to consider the effect of heterogeneity. There is one injector and one producer in this model. The simulation model and the permeability distribution are shown in Fig. 5. The porosities for each gridblocks are calculated using the permeabilities using to the following correlation (Abbasi Asl et al. 2010):

$\emptyset=\left(\frac{k}{2 \times 10^{9}}\right)^{1 / 8}$

As it is mentioned, optimum salinity for this surfactant/ crude oil/brine solution is about $0.365(\mathrm{meq} / \mathrm{ml})$ and $C_{\mathrm{SEL}}$ and $C_{\mathrm{SEU}}$ are $0.2(\mathrm{meq} / \mathrm{ml})$ and $0.56(\mathrm{meq} / \mathrm{ml})$, respectively. Since the formation brine salinity 1 (meq/ $\mathrm{ml}$ ) is more than optimum salinity, decreasing the

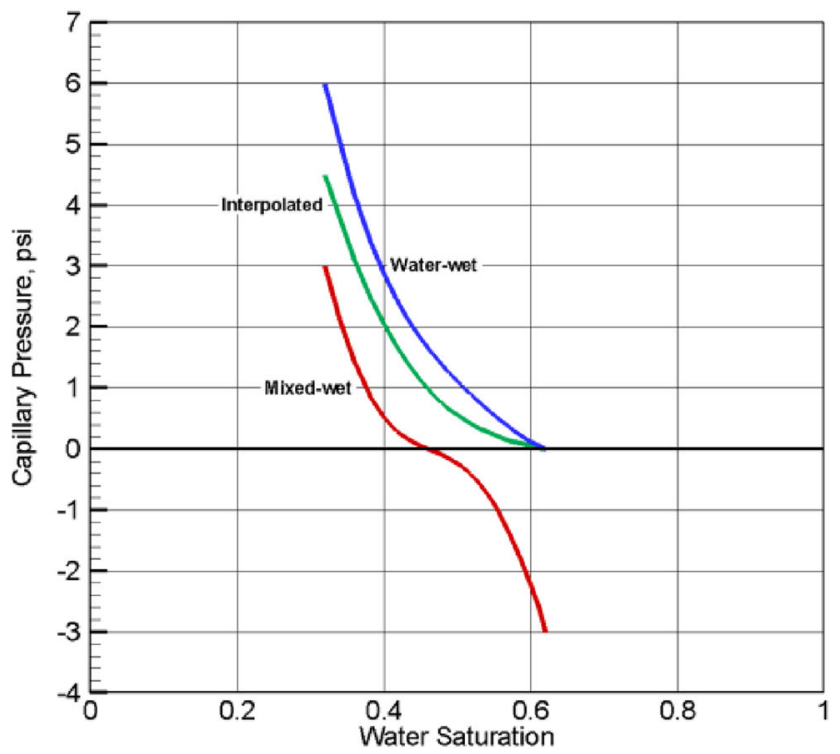

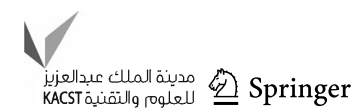



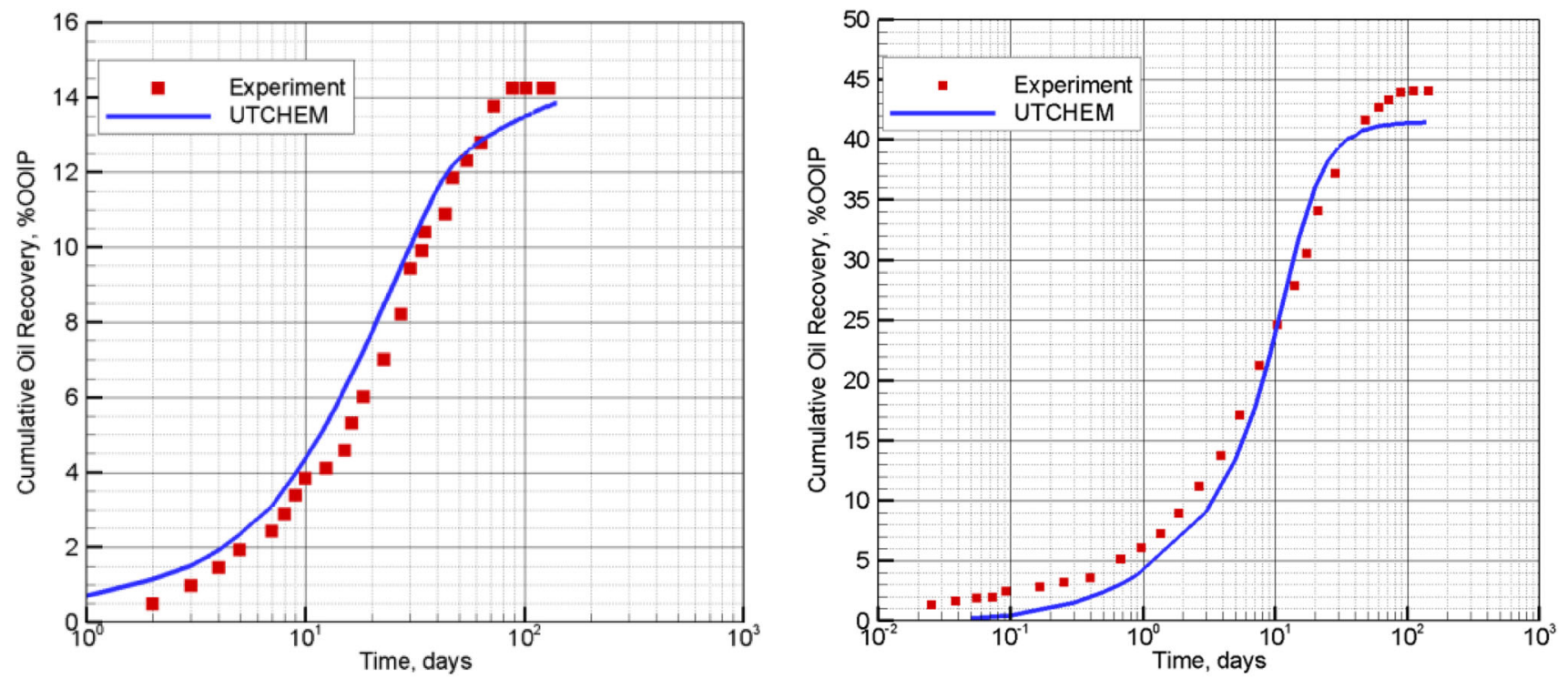

Fig. 4 Comparison of simulated and experiment imbibition cell test, Case C (left), Case B (right)

formation salinity to the near optimum salinity of surfactant phase behavior in order to reach the ultra-low IFT is necessary. This is because the salinity has a significant effect on the surfactant phase behavior so that IFT minimizes at the optimum salinity. In order to evaluate the benefit of combination of surfactant flood with lowsalinity water and the effect of ionic strength of lowsalinity water on the surfactant phase behavior, several simulations are conducted with different ionic strength salinity water as are given in Table 7 .

The effect of the amount of ionic strength of saline water on surfactant is dependent on two important parameters: one is the formation brine salinity and the other is related to surfactant phase behavior (optimum salinity, $C_{\mathrm{SEL}}$, and $\left.C_{\mathrm{SEU}}\right)$. If there is a small difference between the optimum salinity and formation brine salinity, the lowsalinity water not only does not have any positive effect on surfactant phase behavior, but can also affect the surfactant phase behavior negatively. Therefore, to design a combination process of surfactant and low-salinity water, these two important parameters should be considered. Since the formation brine salinity of many reservoirs is higher than 1 $(\mathrm{meq} / \mathrm{ml})$ and the optimum salinity of many industrial surfactants is less than this amount, the combination of surfactant and low-salinity brine can be widely used.

The other benefit of combining low-salinity water with surfactant flooding is the surfactant adsorption which decreases in lower salinity. The effect of surfactant adsorption is modeled based on the laboratory data for this dolomite mixed-wet rock (Levitt et al. 2009). The base case value is assumed to be $0.3 \mathrm{mg} / \mathrm{g}$ rock based on the average laboratory measurement. The curve fitting parameters are adjusted to set the plateau of the curve at the laboratory value.

As it is mentioned, there are two mechanisms for surfactant flooding in order to increase overall oil recovery. The first one is related to fluid-fluid interaction and reducing IFT between water and oil phases. The second one is related to rock-fluid interaction and changing the wettability toward more water-wet condition. To study the effect of each single mechanism separately on oil recovery for this mixed-wet rock, the benefit of surfactant flooding and combination of surfactant and low-salinity water is evaluated without considering the effect of wettability alteration. Second, this process is conducted with considering the effect of wettability alteration. This alteration is more significant in the more oil-wet rocks, and it decreases with initial wettability toward more water-wet. Therefore, the effect of surfactant in wettability alteration plays a more significant role in carbonate rock types than sandstone formations; however, the other parameters such as oil chain, reservoir temperature, brine salinity, and pore throat size can be effective in wettability alteration.

\section{Wettability constant}

In this section, the effect of combination of surfactant with low-salinity water is investigated with the assumption of constant wettability. Prior to surfactant injection, the formation is flooded with formation brine with known well constraints. The average postwaterflood oil saturation and the cumulative oil recovery after $10 \mathrm{PV}$ formation brine injection are plotted as are shown in Figs. 6 and 7, 
Table 6 Relative permeability and capillary pressure parameters

\begin{tabular}{|c|c|c|c|c|c|c|}
\hline & \multicolumn{2}{|c|}{ Mixed-wet } & \multicolumn{2}{|c|}{ Interpolated } & \multicolumn{2}{|c|}{ Water-wet } \\
\hline & Oil & Water & Oil & Water & Oil & Water \\
\hline Residual saturation & 0.42 & 0.32 & 0.40 & 0.32 & 0.38 & 0.32 \\
\hline Endpoint relative permeability & 0.59 & 0.23 & 0.64 & 0.18 & 0.69 & 0.13 \\
\hline Relative permeability exponent & 3.3 & 2.9 & 2.8 & 3.4 & 2.7 & 3.5 \\
\hline Trapping parameters & 10,000 & 10,000 & 30,000 & 1000 & 59,074 & 1865 \\
\hline Capillary pressure endpoint (CPC) & $(-3,3)$ & & 4.5 & & 6 & \\
\hline Capillary pressure exponent (EPC) & 2 & & 2 & & 2 & \\
\hline
\end{tabular}

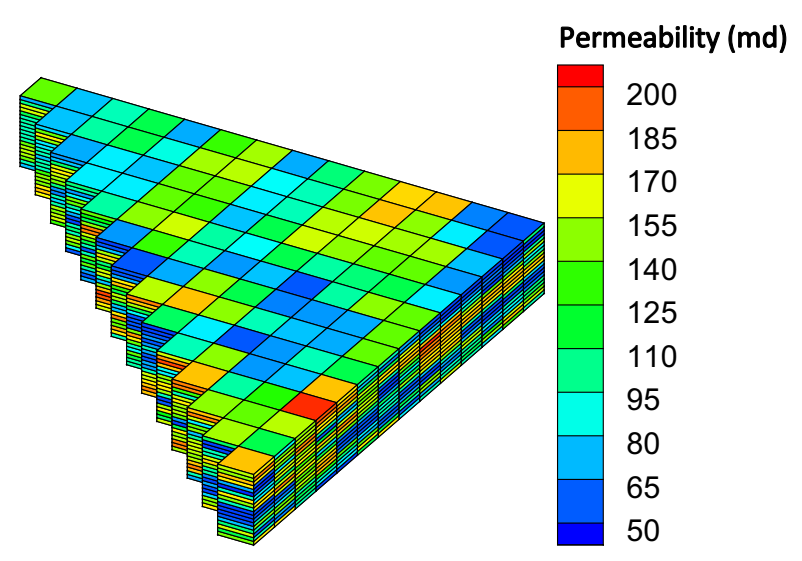

Fig. 5 Permeability distribution (md) of large-scale heterogeneous reservoir

respectively. As it can be seen, the oil recovery is $39 \%$ OOIP after 5 PV and cannot exceed $41 \%$ of total OOIP after 10 PV fluid injections. As Kamath et al. (2001) and Tie and Morrow (2005) have been reported, the effect of waterflooding on overall oil recovery from low permeability carbonate rocks is almost in the order of $40 \%$ of OOIP. As a result, the waterflood residual oil saturation may not be far away from the reported values in this mixed-wet rock; however, the effect of waterflooding is more effective in more water-wet and high permeability rocks. For this reason, the necessity of surfactant flooding to get more oil recovery becomes more obvious in such mixed-wet and low permeability rocks.

In order to consider the effect of surfactant flooding on the overall oil recovery, a $0.3 \mathrm{PV}$ surfactant slug and formation brine (1\% surfactant volume fraction) is injected after 5 PV waterflooding, followed by $4.7 \mathrm{PV}$ formation brine (Case \#1). The average oil saturation after $10 \mathrm{PV}$ is shown in Fig. 6. It is distinguishable that surfactant flooding via decreasing IFT leads to mobilization of more oil compared with waterflooding. The overall oil recovery during the process is also plotted in Fig. 7. The difference in overall oil recovery between surfactant flooding and waterflooding keeps increasing and reaches just above 4 and 5\% of total OOIP after 8 and 10 PV fluid injections, respectively.

The first study of the benefit of surfactant and lowsalinity combination is investigated in Case \#2. The only difference compared with Case \#1 is the ionic strength of water in the surfactant slug and the following water postflush which is $0.5(\mathrm{meq} / \mathrm{ml})$. This amount of salinity is more than optimum salinity of the surfactant phase behavior and less than $C_{\mathrm{SEU}}$. While the injected water salinity is less than $C_{\mathrm{SEU}}$ in order to form Winsor Type III, it is difficult to meet this condition because of considerable difference between initial formation brine salinity and injected water salinity. Due to dispersion, this difference leads to increasing the effective salinity in the reservoir to

Table 7 Model parameters

\begin{tabular}{|c|c|c|c|c|c|}
\hline \multirow[t]{2}{*}{ Surfactant slug } & \multicolumn{5}{|c|}{$\begin{array}{c}0.3 \mathrm{PV} \\
1 \% \text { volume fraction }\end{array}$} \\
\hline & Case \#1 & $\underline{\text { Case \#2 }}$ & Case \#3 & $\underline{\text { Case \#4 }}$ & $\underline{\text { Case \#5 }}$ \\
\hline Salinity $(\mathrm{meq} / \mathrm{ml})$ & 1 & 0.5 & 0.365 & 0.25 & 0.1 \\
\hline \multirow[t]{2}{*}{ Water postflush } & \multicolumn{5}{|c|}{ 4.7 PV } \\
\hline & $\underline{\text { Case \#1 }}$ & $\underline{\text { Case \#2 }}$ & $\underline{\text { Case \#3 }}$ & $\underline{\text { Case \#4 }}$ & $\underline{\text { Case \#5 }}$ \\
\hline Salinity $(\mathrm{meq} / \mathrm{ml})$ & 1 & 0.5 & 0.365 & 0.25 & 0.1 \\
\hline Surfactant adsorption (mg/g rock) & \multicolumn{5}{|c|}{0.3} \\
\hline
\end{tabular}


more than $C_{\mathrm{SEU}}$, especially in the beginning of the process. The effective salinity and surfactant concentration versus dimensionless distance between injection and production wells in the 10th layer of the reservoir model at 0.2, 0.4, and 0.6 PV after waterflooding are compared in Fig. 8. As it can be seen, the effective salinity at 0.2 and $0.4 \mathrm{PV}$ after waterflooding did not change the reservoir salinity to less than $C_{\mathrm{SEU}}$; however, the effective salinity of the reservoir almost reached the lower level than $C_{\mathrm{SEU}}$ after $0.6 \mathrm{PV}$. This observation shows that the injected $0.5(\mathrm{meq} / \mathrm{ml})$ salinity water is not suitable to pass the surfactant phase behavior from Winsor Type III in active region where the surfactant concentration is more in order to reach the lowest amount of IFT.

The overall oil recovery in Case \#2 has increased to about $49.5 \%$ of total OOIP due to the low-salinity waterflooding (Fig. 7). While the surfactant/crude oil/brine phase behavior is not completely in Winsor Type III, it caused about $4 \%$ more oil recovery compared with surfactant flooding with formation brine salinity after $10 \mathrm{PV}$. There are some reasons for this improved recovery. The one that seems more important is the forming of the microemulsion system close to Winsor Type III after 0.6 PV surfactant injections. The other reason is the amount of surfactant adsorption which decreased with reduction in the amount of salinity.

In Case \#3, the water salinity of surfactant slug and the following water postflush is decreased to the optimum salinity of surfactant phase behavior $0.365(\mathrm{meq} / \mathrm{ml})$. As it can be seen from Fig. 9, the effective salinity at $0.2 \mathrm{PV}$ after waterflooding did not drop to less than $C_{\mathrm{SEU}}$ due to the larger difference with initial formation salinity and the dispersion effect and consequently, based on the concentration of surfactant at this time, the surfactant/crude oil/ brine phase behavior is at Winsor Type $\mathrm{II}(+)$; however, 0.4 $\mathrm{PV}$ after waterflooding is enough to change the effective salinity to less than $C_{\mathrm{SEU}}$. At this time, the effective salinity became closer to the optimum salinity in active region where the surfactant concentration is at highest level and as a result the microemulsion system is at Winsor Type III. In this case, the effective salinity at $0.6 \mathrm{PV}$ after waterflooding in most significant part of the reservoir become more and more close to the optimum salinity and it can be inferred that IFT almost reaches the lowest amount.

The amount of oil recovery in Case \#3 has improved to about $53 \%$ of total OOIP after 10 PV fluid injections (Fig. 7), 7\% more than surfactant flood with 0.5 (meq/ml) brine salinity. As previously discussed, this is because of the microemulsion phase behavior and surfactant adsorption which decreases by low-salinity water. Using lowsalinity preflush before surfactant injection can be one efficient strategy in order to reach the optimum salinity from the beginning of the surfactant injection for this reservoir; however, this approach causes a problem because soft water preflush leads to increasing the contact of the viscous surfactant slug with the formation rock which is bypassed by the preflush (Chiou and Chang 1978).

In Case \#4, the amount of water salinity of surfactant slug and the following water postflush is decreased to less than the optimum salinity and more than $C_{\mathrm{SEL}} 0.25$ (meq/ $\mathrm{ml}$ ). In this case, the effective salinity declines to about $C_{\mathrm{SEU}}$ at $0.2 \mathrm{PV}$ after waterflooding in the active region (Fig. 10). It can also be seen that the effective salinity is reaching the optimum salinity in the active region at $0.4 \mathrm{PV}$ after waterflooding; however, the effective salinity drops to a lower level than the optimum salinity and close to the $C_{\mathrm{SEL}}$ in most of the reservoir after $0.6 \mathrm{PV}$ surfactant injections. In this condition, the solubility of surfactant in water increases and surfactant moves thorough the porous medium faster. It can be inferred that the effective salinity is far away from the optimum salinity in major portion of surfactant injection time and consequently, the ultra-low IFT is not achieved.
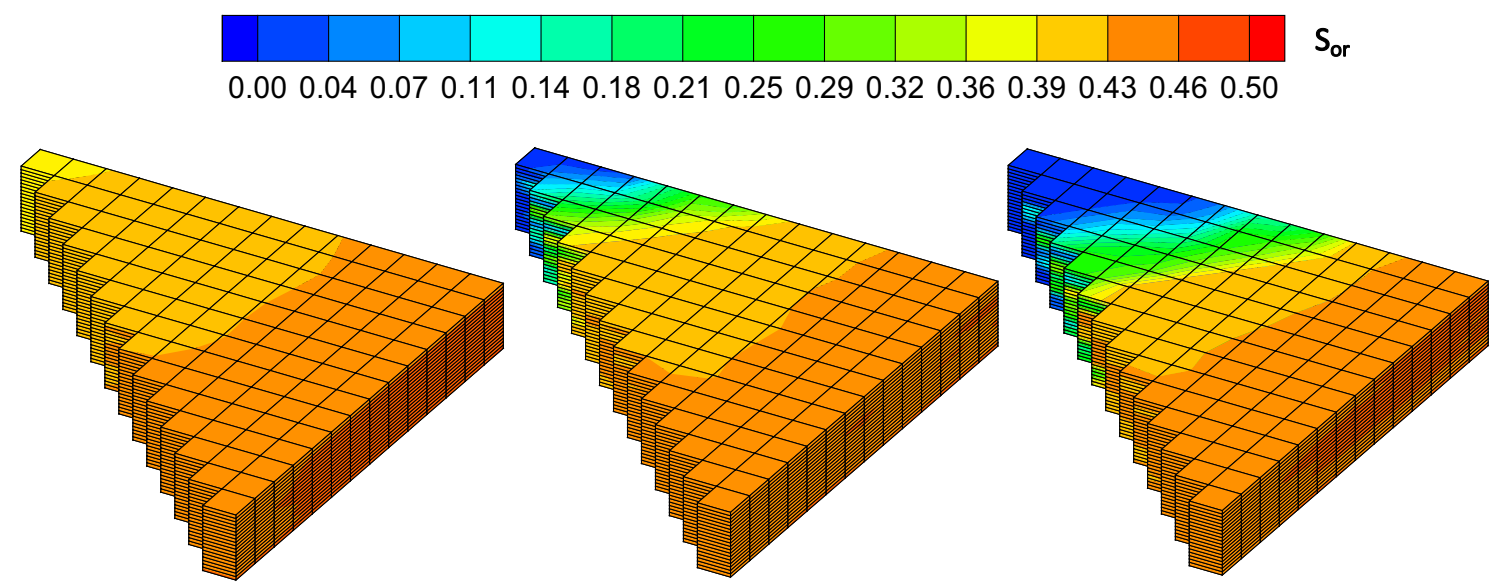

Fig. 6 Oil saturation after waterflooding (left), surfactant (middle), and surfactant and optimum salinity (right)

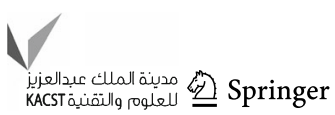



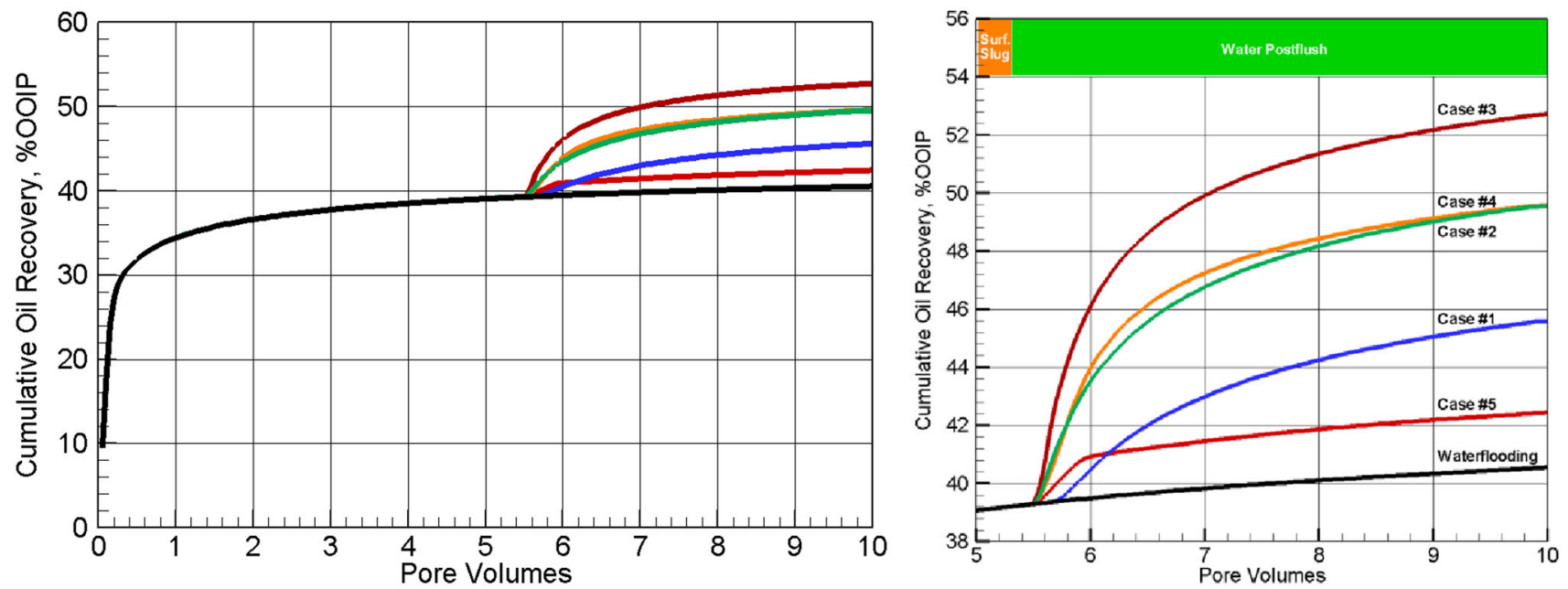

Fig. 7 Oil recovery for different injection scenarios

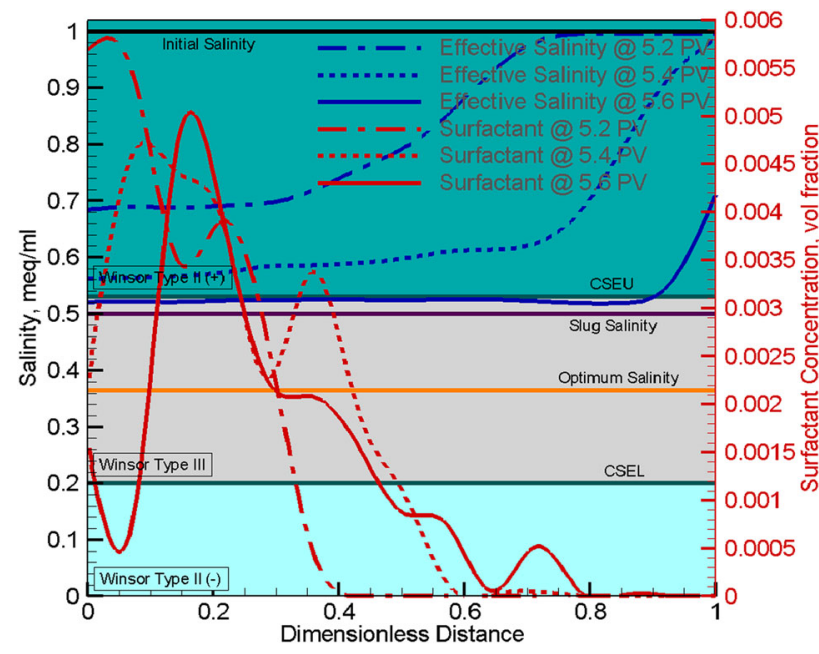

Fig. 8 Simulated salinity and surfactant concentrations in 10th layer for Case \#2

Comparing Cases \#4 and \#3, it can be concluded that while at the beginning of surfactant injection the effective salinity in Case \#3 is further away from the optimum salinity, the effective salinity in this case becomes closer to the optimum salinity after 0.6 PV surfactant slug injection and remains at this condition until the end of the process. On the other hand, the effective salinity in Case \#4 after 0.6 PV surfactant injection falls to a lower level than optimum salinity and because close to the $C_{\mathrm{SEL}}$, and thereafter remains in this condition until the end of process. It means that IFT during most of the surfactant injection time in Case \#3 is at the lowest level compared to Case \#4. While the surfactant adsorption is lower in Case \#4 because of the lower salinity, the results prove that the effect of ultra-low IFT is more significant than the effect of surfactant adsorption. Therefore, the cumulative oil recovery of Case \#4 rises to $49.5 \%$ of total

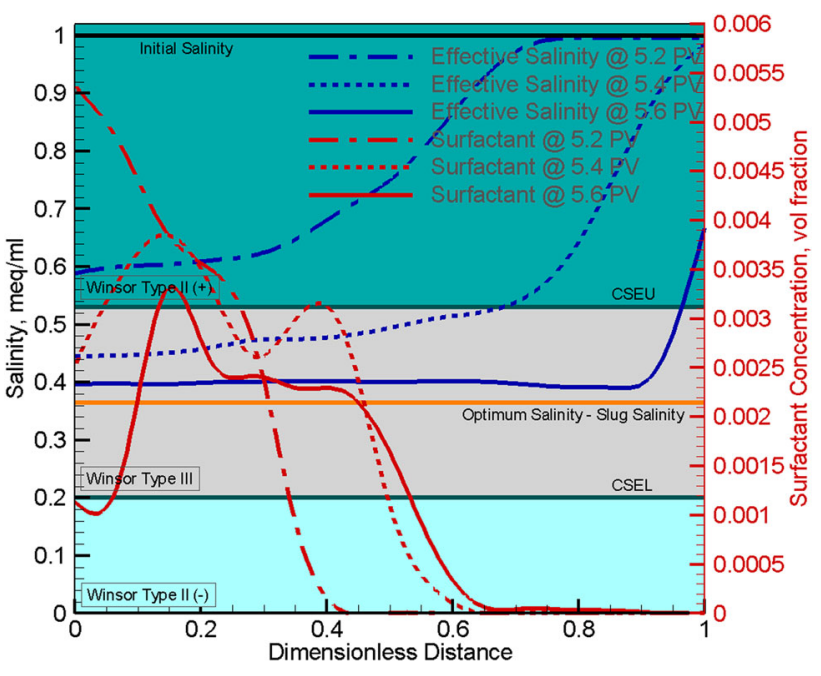

Fig. 9 Simulated salinity and surfactant concentrations in 10th layer for Case \#3

OOIP at the end of process while there is not any difference between these two cases until the end of 0.6 PV surfactant injections as shown in Fig. 7.

Comparing Cases \#4 and \#2, it can be observed that the effective salinity is above $C_{\mathrm{SEU}}$ before $0.6 \mathrm{PV}$ surfactant injections in Case \#2, but in Case \#4 it drops to the optimum salinity during this period of surfactant injection. For this reason, the overall oil recovery in Case \#4 was more than Case \#2 until the end of 9 PV fluid injections; however, the final oil recoveries in these two cases are the same. This is due to the fact that during most of the surfactant flooding time, the effective salinity is far away from the optimum salinity and it was close to $C_{\mathrm{SEU}}$ and $C_{\mathrm{SEL}}$ in Case \#2 and Case \#4, respectively. The solubility of surfactant is more in water phase in Case \#4; however, this solubility is more in the oil phase in Case \#2. Therefore, the 


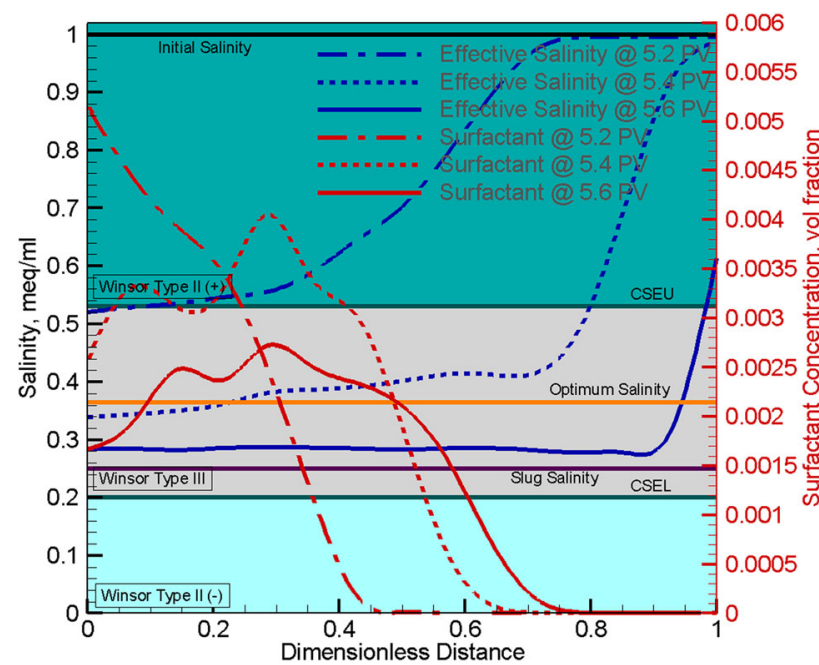

Fig. 10 Simulated salinity and surfactant concentrations in 10th layer for Case \#4

breakthrough time of the injected surfactant in Case \#4 is shorter than Case \#2.

In Case \#5, the level of water salinity of the surfactant slug and the following water postflush is decreased to less than both optimum salinity and $C_{\mathrm{SEU}} 0.1$ (meq/ml). As it can be seen in Fig. 11, the effective salinity is in Winsor Type III region until the end of 5.6 PV injected and after that it drops to the lower level than $C_{\mathrm{SEL}}$ and stayed in Winsor Type II(-) until the end of the fluid injection. In this condition, while the surfactant adsorption declines due to low-salinity water, the most of the injected surfactant partitions into water phase and achieving the ultra-low IFT is thus impossible.

Comparing Cases \#5 and \#1, it can be observed that at the beginning of fluid injection, the effective salinity in Case \#5 is close to the optimum salinity so that overall oil is recovered until the end of $6.2 \mathrm{PV}$ injected as shown in Fig. 7. It is proved that while the salinity drops to 0.1 (meq/ $\mathrm{ml}$ ), the overall oil recovery reaches just over $42 \%$ of OOIP and could not surpass the oil recovery resulting from surfactant injection with formation brine salinity. It can be concluded that the combination of surfactant and lowsalinity water does not always lead to more oil recovery while the surfactant adsorption reduces. For this reason, in order to make the most of the combinations of surfactant and low-salinity water, a careful design is needed. In addition, it should be taken into consideration that surfactant phase behavior parameters such as optimum salinity, $C_{\mathrm{SEU}}, C_{\mathrm{SEL}}$, and initial formation brine salinity play a considerable role to obtain the highest amount of overall oil recovery.

It should be noted that the conclusions from these results are just based on the concept of surfactant/crude oil/brine phase behavior and without the consideration of the

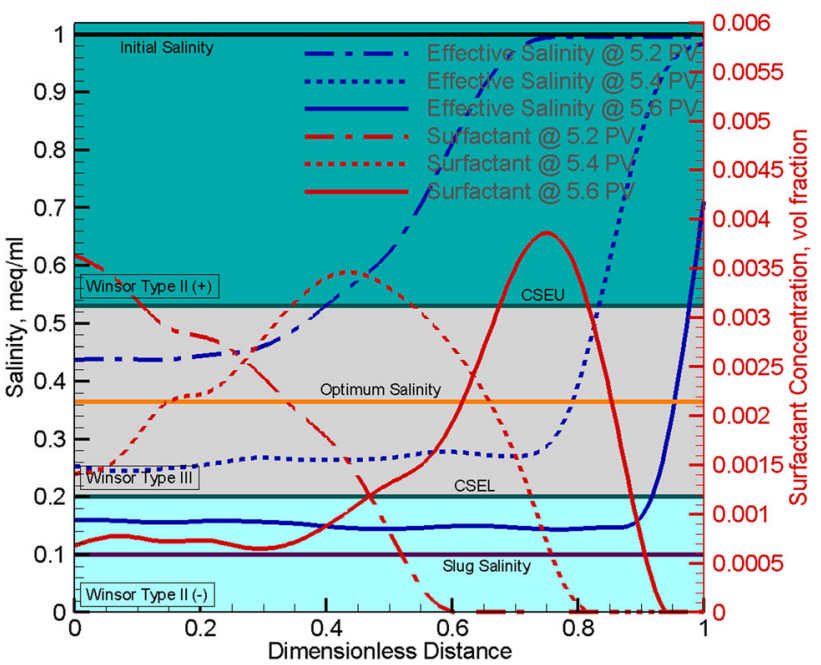

Fig. 11 Simulated salinity and surfactant concentrations in 10th layer for Case \#5

wettability alteration effect, i.e., what low-salinity water and surfactant flood can cause, especially in mixed- and oil-wet rock formations. The injection of low-salinity water can also lead to changes in the wettability; however, due to the complexity of the crude oil/brine/rock interactions, the mechanisms behind a low-salinity water process have been debated in the literature for the last decade. Data for the effect of salinity on oil recovery present contrasting trends because the mechanisms of low-salinity water are still uncertain. In many research articles, the efficiency of lowsalinity water in improving oil recovery is exhibited (Webb et al. 2004; Robertson 2007; Lager et al. 2008); however, in some other studies, oil recovery improvement is never observed (Filoco and Sharma 1998; Zhang et al. 2007). This contradiction comes from the fact that low-salinity water injection changes wettability form oil-wet toward water-wet. The change in electric charge at rock-fluid and fluid-fluid interfaces caused by low-salinity water is the primary reason for wettability alteration. When the electric charges become more negative at interfaces, the repulsion forces between rock and oil increase and make the rock more water-wet. As a result, low-salinity water might not be efficient for changing the wettability in certain cases where the rock wetting conditions are water-wet and surface charge is initially more negative (sandstone formations).

Simulated IFT profiles in all cases are compared at 0.4 and $0.6 \mathrm{PVs}$ surfactant injections after waterflooding in 10th layer of the reservoir (Fig. 12). As it can be seen, IFT in Case \#3 reaches the lowest amount and it can march through the reservoir as time goes on. It can be concluded that IFT in Case \#3 which is the combination of surfactant with optimum salinity water leads to the lowest level of IFT, and in consequence yields higher oil recovery. The 
other distinguishable note is that the propagation of the injected surfactant, which is faster in lower salinity water due to solubility ability of surfactant in water at lower salinity; however, in the salinity region with higher level than $C_{\text {SEU }}$, most of the surfactant partitions in trapped oil. This concept is more distinguishable at more injection time (0.6 PV). As a result, at these conditions, higher amounts of surfactant should be injected to produce more oil and this is not cost-effective.

\section{Determining flood performance from interwell tracer test analysis}

Tracer test simulation is also performed to estimate the average oil saturation within the swept pore volume at the end of each recovery mode. Estimating volume swept by injected fluids from tracers is first developed by Danckwerts (1953) and Deans (1978) for reactor beds and porous media, respectively. Asakawa (2005) has extended a general derivation of the moments to include three-dimensional, heterogeneous reservoirs including naturally fractured reservoirs. In simplest form, the swept pore volume is determined from the mean residence volume of a conservative tracer. For a tracer injected as a slug, the mean residence volume is also determined from tracer concentration histories at the production well.

The swept pore volume $\left(V_{\mathrm{s}}\right)$ is defined as the pore volume of the reservoir contacted by the injected fluid. This parameter can be calculated from the produced tracer concentrations as follows:

$V_{\mathrm{s}}=\frac{\overline{V_{2}}\left(K_{1}-1\right)-\overline{V_{1}}\left(K_{2}-1\right)}{K_{1}-K_{2}}$

where $\overline{V_{1}}$ and $\overline{V_{2}}$ are the mean residence volumes of the tracers and $K_{\mathrm{i}}$ are their partitioning coefficients. The partitioning coefficient of tracer $\mathrm{i}$ is defined as follows:

$K_{\mathrm{i}}=\frac{C_{\mathrm{io}}}{C_{\mathrm{iw}}}$

where $C_{\mathrm{io}}$ and $C_{\mathrm{iw}}$ are the concentrations of tracer $\mathrm{i}$ in oil and water phases, respectively.

Tracer tests, interwell and single well, have been used to determine oil saturation for decades (Cooke 1971; Tomich et al. 1973; Deans 1978; Tang 2005; Khaledialidusti et al. 2014, 2015a, b). The interwell method consists of two or more non-reacting tracers with different partitioning coefficient between oil and water phases being injected into the formation. Partitioning coefficients are measured in the laboratory. Different partitioning coefficients of tracers lead to different arrival times of tracers to the production well. Using mean residence volume of two tracers with different partitioning coefficients, the average oil saturation in the swept pore volume can be calculated as follows:
$\overline{S_{\mathrm{or}}}=\frac{\overline{V_{1}}-\overline{V_{2}}}{\overline{V_{2}}\left(K_{1}-1\right)-\overline{V_{1}}\left(K_{2}-1\right)}$

For a tracer slug during two-phase flow of oil and water, $\overline{V_{\mathrm{i}}}$ is defined as follows:

$\overline{V_{\mathrm{i}}}=\frac{\int_{0}^{\infty} \mathrm{q} C_{\mathrm{it}} \mathrm{tdt}}{\int_{0}^{\infty} C_{\mathrm{it}} \mathrm{dt}}-\frac{V_{\text {slug }}}{2}$

where $C_{\mathrm{it}}, \mathrm{q}, V_{\text {slug }}$, and t are the total concentration of tracer $\mathrm{i}$, the liquid flow rate, the volume of tracer slug, and time, respectively.

The total effluent tracer concentration is defined as follows:

$C_{\mathrm{it}}=f_{\mathrm{w}} C_{\mathrm{iw}}+f_{\mathrm{o}} C_{\mathrm{io}}$

where $f_{\mathrm{w}}$ and $f_{\mathrm{o}}$ are the fractional flow of oil and water, respectively.

One conservative and two partitioning tracers $\left(K_{\mathrm{i}}=1\right.$ and 2) are injected for $0.3 \mathrm{PV}$ after each recovery injections when the oil cut reached almost zero and are followed by 2.7 PV of water injection with no tracer added. Normalized tracer concentration history and swept pore volume after waterflooding, surfactant flooding, and combination of surfactant flooding and optimum salinity are shown in Figs. 13, 14, and 15, respectively. From the concept of the tracer partitioning coefficient, it can be inferred that the travel time of partitioning and non-partitioning tracers in the production well decrease as average oil saturation drops. Therefore, the peaks of the tracer concentrations get closer as the average oil saturation decreases.

Calculated oil saturations for each pair of tracers are listed in Table 8 . The average oil saturation within the swept pore volume at the end of waterflooding is determined to be about 0.36 . This average oil saturation drops to about 0.33 and 0.29 , respectively, after surfactant flooding and a combination of surfactant and optimum salinity flooding. Comparison of the obtained results makes the importance of the benefit of combining surfactant with optimum salinity water, more obvious. It can be concluded that a suitable design of combining surfactant with lowsalinity water can lead to much higher oil recoveries compared to surfactant flooding, due to the fact that the formation brine salinity is higher than the optimum salinity of the surfactant phase behavior.

\section{Secondary versus tertiary response}

It is generally believed that the early implementation of every special EOR method yields higher oil recovery. To investigate the effect of surfactant flooding in secondary and tertiary recovery, these scenarios are compared at 10 $\mathrm{PV}$. In the design of secondary recovery, waterflooding is stopped and 0.3 PV surfactant slug without low-salinity 

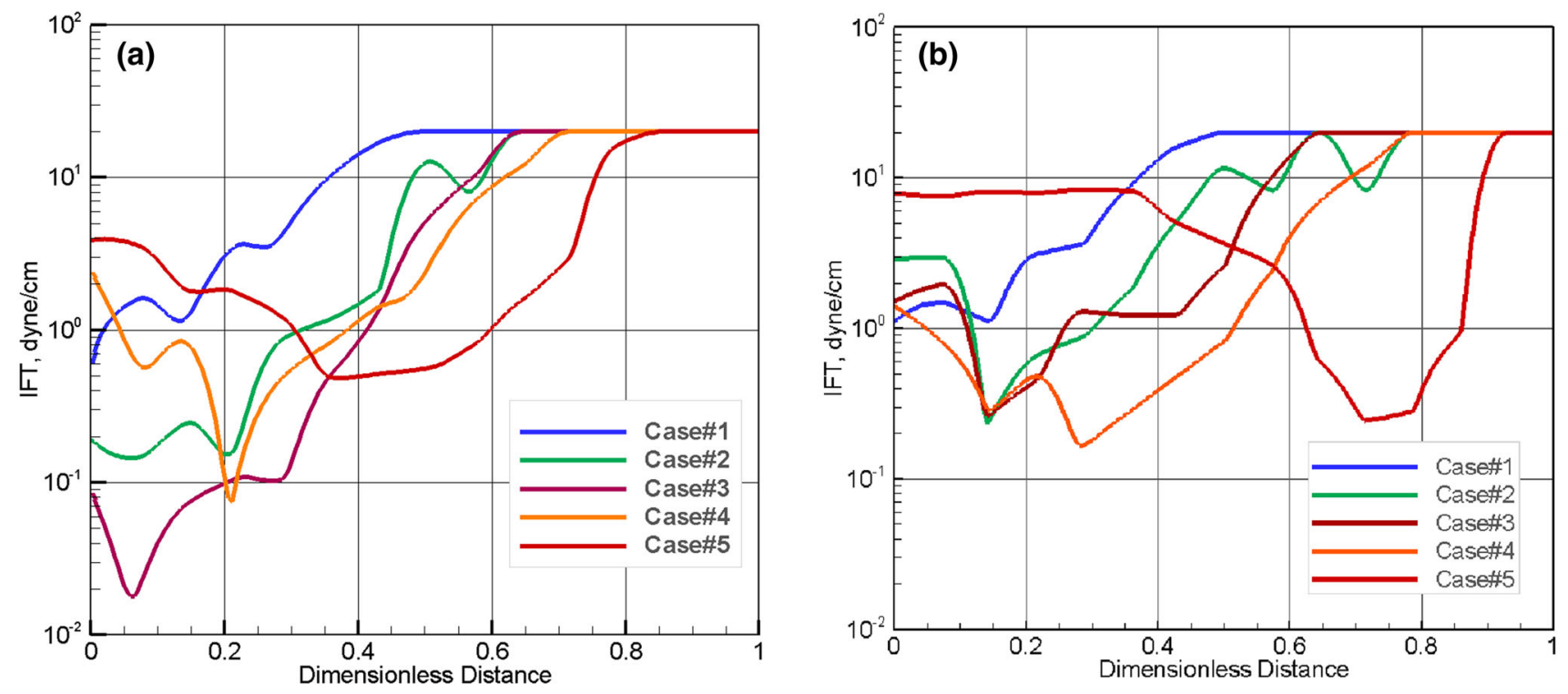

Fig. 12 Simulated IFT profile: a 0.4 PV after waterflood, b 0.6 PV after waterflood

water is injected and then followed by the injection of formation brine. In the design of tertiary recovery, a $0.3 \mathrm{PV}$ surfactant slug with formation brine is injected following 5.0 PV waterflooding with formation brine. This is then followed by formation brine injection. In this investigation, the effect of combination low-salinity is not studied. The effects of these two strategies are compared in Fig. 16. As it can be seen, that secondary recovery is more effective than the tertiary recovery in terms of timing and oil recovery. While the amount of oil recovery at the end of 10 PV fluid injections in the secondary recovery case is about $47 \%$, the tertiary recovery case is just under $46 \%$ and oil recovery did not exceed $40 \%$ for waterflooding. The large difference between the secondary and tertiary oil recovery becomes more obvious when oil recovery is compared with respect to timing. In secondary recovery, more oil recovery is achievable in short times. While oil recovery was about $45 \%$ after 4 PV in secondary recovery, 9 PV fluid injections were needed to reach the same amount in tertiary oil recovery. All in all, in this reservoir model study and based on the recovery modes discussed, secondary recovery is more efficient than tertiary recovery mode because it leads to earlier oil recovery.

\section{Wettability alteration}

In the previous section, the effect of first mechanism of surfactant flooding, surfactant phase behavior effects lead to ultra-low IFT, without considering the second mechanism, wettability alteration, is investigated. The mechanism of wettability alteration is quite dependent on the initial wettability of the formation rock. In more oil-wet rocks, this alteration is more significant toward water-wet condition, and in consequence, the overall oil recovery is more significant; however, in more water-wet rocks, this alteration is weaker and as a result exhibits less impact on the cumulative oil recovery. In this section, the effect of wettability alteration is evaluated based on the petrophysical data obtained from the imbibition cell simulation.

As is discussed, the initial wettability of this dolomite rock is considered mixed-wet based on the available data and using the surfactant imbibition cell simulation. Then, the wettability of rock is changed gradually toward more water-wet in order to match the oil recovery with experiment results. The best match is obtained from interpolated data between mixed-wet and water-wet condition because wettability alteration is a gradual and not a pulse process as it is shown in Fig. 3; Table 6.

In order to investigate the effect of wettability alteration on this mixed-wet dolomite rock, surfactant flooding without low-salinity water (Case \#1) is performed first and then the effect of wettability alteration via surfactant slug and the following water postflush at optimum salinity (Case \#3) is investigated.

The total oil recoveries related to Case \#1 in different wettability conditions are compared (Fig. 17). As expected, the oil recovery with relative permeability and capillary pressure representing water-wet condition gave higher recovery of about $51 \%$ OOIP after 10 PV fluid injections; however, it is also determined that the surfactant flooding in constant wettability condition leads to improvement in oil recovery of about $45.5 \%$ OOIP. This improvement is just due to reduction in IFT. The oil recovery based on the data obtained from the best match by surfactant imbibition 

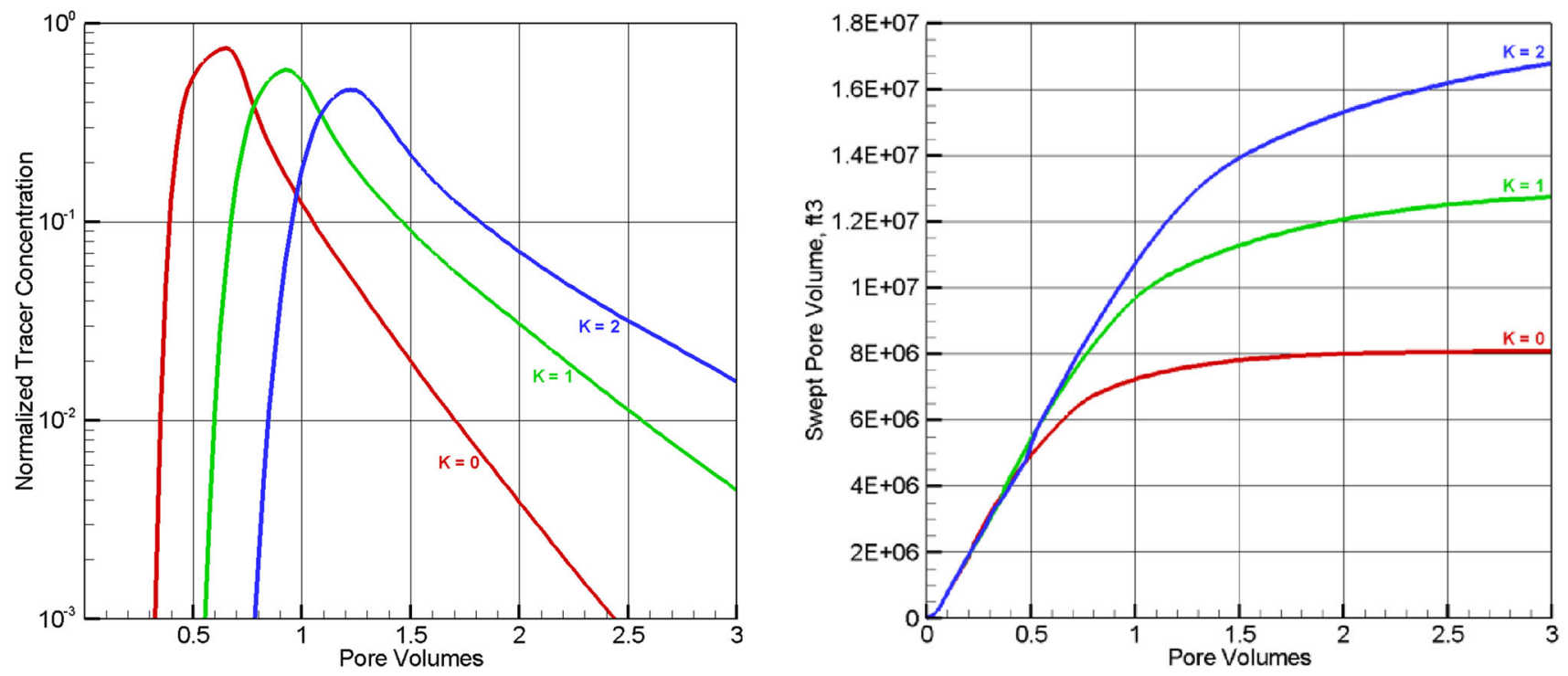

Fig. 13 Tracer concentration histories (left), swept pore volume calculated from the tracer test simulation (right): following the waterflood
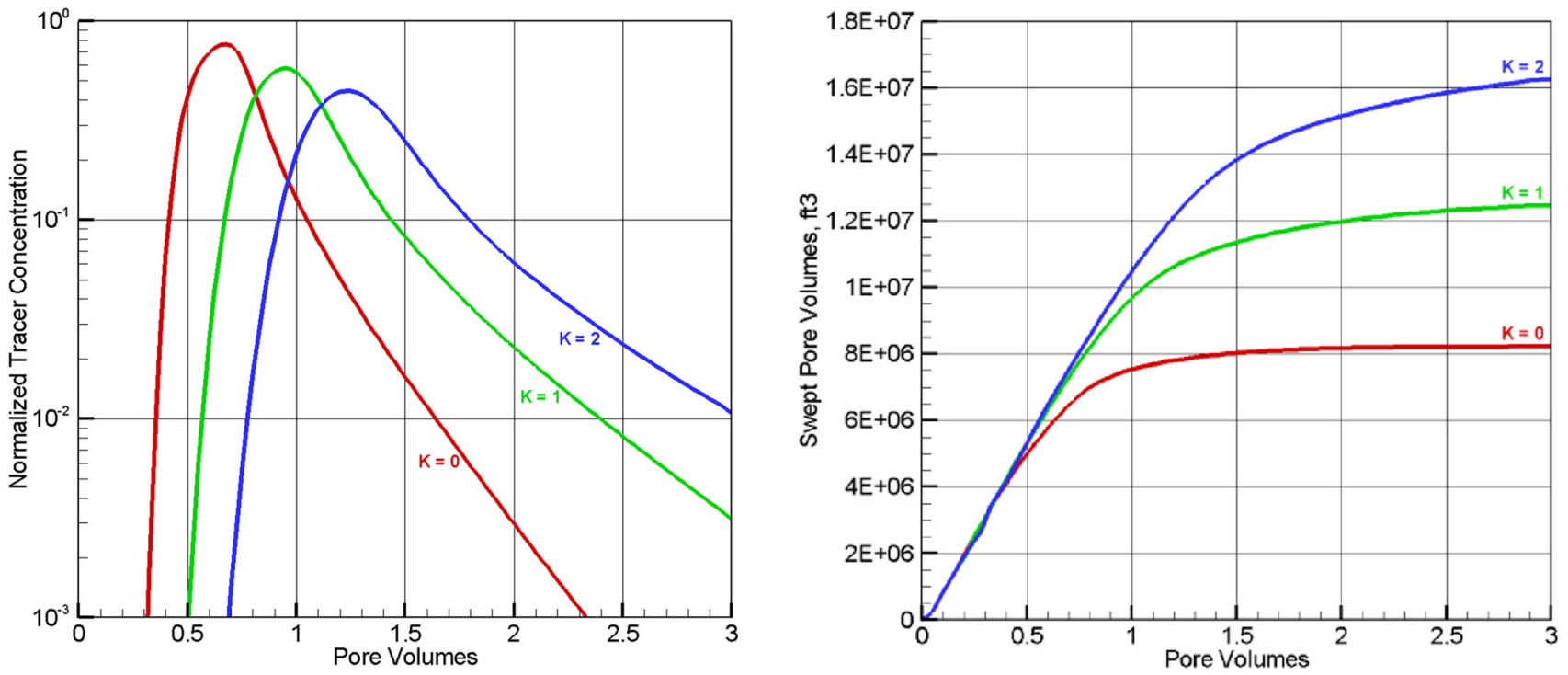

Fig. 14 Tracer concentration histories (left), swept pore volume calculated from the tracer test simulation (right): following the surfactant flood

simulation leads to an increase in oil recovery of just over $49 \%$ OOIP.

Comparing these obtained oil recoveries with the recovery resulted by waterflooding $(40.5 \%$ OOIP), it can be concluded that the portion of IFT reduction and wettability alteration in oil recovery was about 5 and $3.5 \%$, respectively, at the end of $10 \mathrm{PV}$ fluid injection. It should be noted that these portions of surfactant mechanisms in overall oil recovery may be completely different in other reservoirs with different initial wettability, temperature, crude oil, and salinity.

After evaluation of the effect of wettability alteration for surfactant flooding with formation brine salinity, this effect is also investigated in the case of combining surfactant with optimum salinity (Case \#3).

Since this rock initially is mixed-wet and the formation salinity is quite high 1 ( $\mathrm{meq} / \mathrm{ml})$, the probability of changing wettability by low-salinity water $0.365(\mathrm{meq} / \mathrm{ml})$ is high. Consequently, the wettability alteration affected by low-salinity water as a single EOR project mode in tertiary recovery is also evaluated. In this study, in order to investigate the effect of low-salinity water in wettability alteration, the water-wet and interpolated data obtained from surfactant imbibition simulation are used. Since there is no data on wettability alteration via low-salinity water for this dolomite rock, this assumption can give us only a 

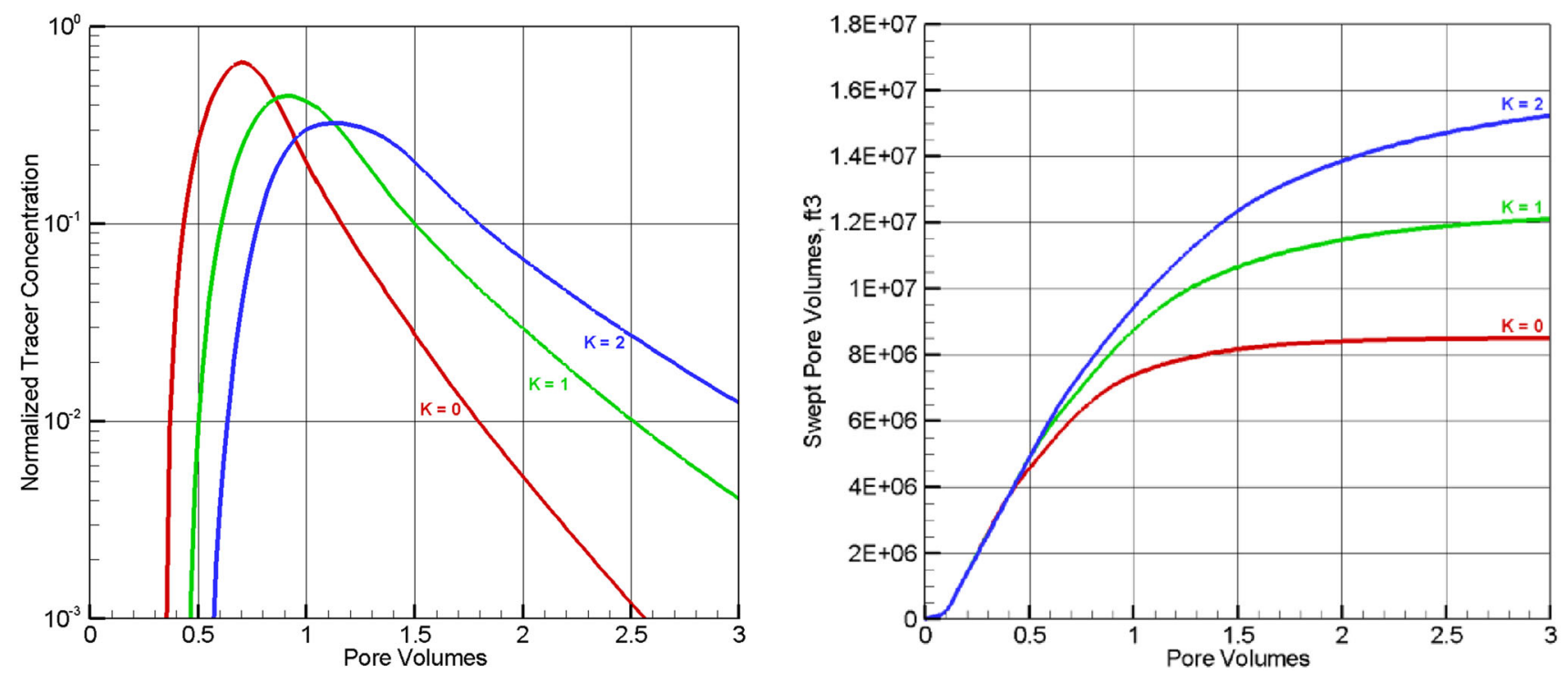

Fig. 15 Tracer concentration histories (left), swept pore volume calculated from the tracer test simulation (right): surfactant and optimum salinity flood

Table 8 Oil saturation calculated using mean residence volumes of tracers

\begin{tabular}{lll}
\hline & $\begin{array}{l}\text { Using tracer 1 } \\
\text { and 2 } \\
(K=0,1)\end{array}$ & $\begin{array}{l}\text { Using tracer 1 } \\
\text { and 3 } \\
(K=0,2)\end{array}$ \\
\hline Waterflooding & 0.363 & 0.36 \\
$\begin{array}{l}\text { Surfactant flood } \\
\begin{array}{l}\text { Combination of surfactant and } \\
\text { optimum salinity }\end{array}\end{array}$ & 0.33 & 0.326 \\
\hline
\end{tabular}

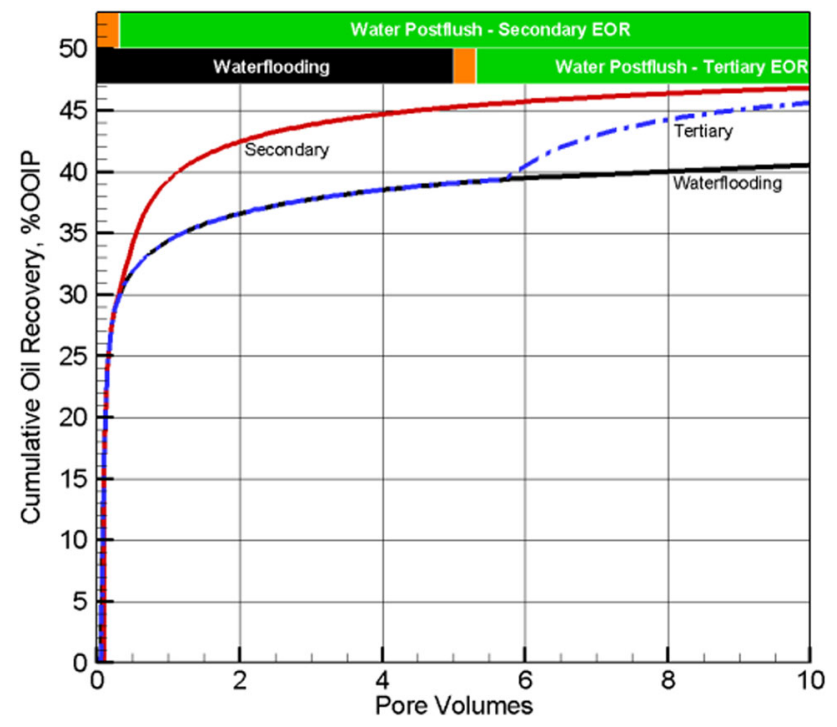

Fig. 16 Comparison of surfactant flood (Case \#1) under secondary and tertiary conditions general understanding of the effect of low-salinity water in wettability alteration.

As it can be seen in Fig. 18, low-salinity water in waterwet condition leads to an improvement in oil recovery of about $7 \%$ OOIP over waterflooding at the end of the process; however, because of the gradual alteration in wettability alteration the obtained result, according to interpolated data, can be closer to reality. Low-salinity water in this condition causes a higher improvement in oil recovery of about $5 \%$ OOIP compared to waterflooding after 10 PV fluid injections.

After evaluating the effect of $0.365(\mathrm{meq} / \mathrm{ml})$ salinity water, the effect of combining surfactant and low-salinity water with considering wettability alteration is also investigated. There was also no data regarding wettability alteration as a result of combining surfactant and lowsalinity water in this dolomite rock. As a result, the relative permeability and capillary pressure obtained from surfactant imbibition simulation (Table 6) are also used for this combination; however, according to the effect of lowsalinity water for changing the wettability, the probability of water-wet condition close to the reality is more than for the interpolated case.

The combining of surfactant and optimum salinity water in constant wettability condition is evaluated in order to understand the portion of IFT reduction in improvement of oil recovery. As it can be seen in Fig. 18, this combination leads to an improvement in overall oil recovery of about $12 \%$ OOIP compared to waterflooding. It can be concluded that the effect of IFT reduction by optimum salinity water is more effective than the effect of wettability alteration of water injection with optimum salinity as a single EOR 


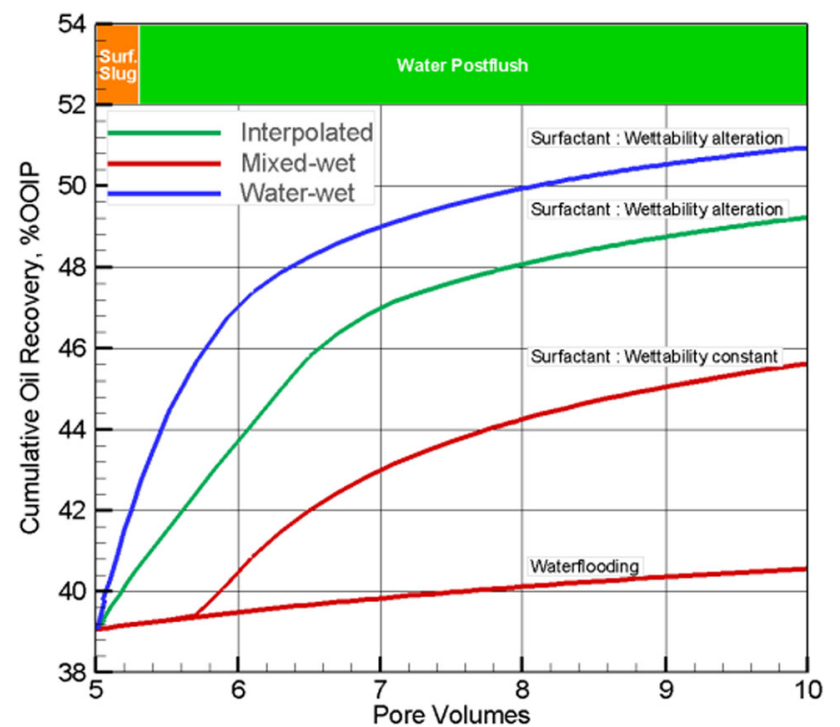

Fig. 17 Comparison of incremental oil recovery of surfactant flood (Case \#1) in different wettability condition

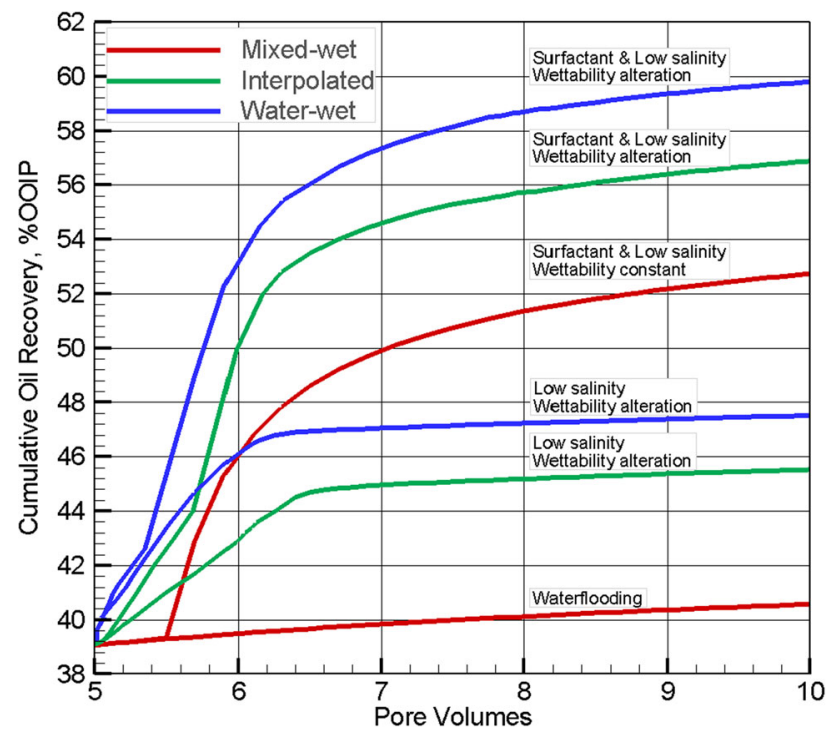

Fig. 18 Comparison of incremental oil recovery of low-salinity water and combination of surfactant and low-salinity water at optimum salinity (Case \#3) in different wettability condition

project. This combination also leads to an improvement in oil recovery of just under 16.5 and $19.5 \%$ OOIP in interpolated and water-wet case, respectively, compared to waterflooding.

All in all, it can be concluded that the combination of surfactant flooding and low-salinity water at optimum salinity level of the surfactant phase behavior can have the highest efficiency on cumulative oil recovery. In addition, in this rock type, the mechanism of IFT reduction plays a more significant role than the mechanism of wettability alteration; however, the effect of wettability alteration in recovery increases as initial wettability gets in more oil-wet condition.

\section{Summary and conclusions}

- Surfactant flooding due to combined effect of fluidfluid interaction by decreasing IFT and rock-fluid interaction by altering the wettability is an efficient EOR method, especially for oil- and mixed-wet reservoirs.

- Matching the modeled data with the result of surfactant spontaneous imbibition test in the case which is not aged using a specific relative permeability, capillary pressure, and CDC parameters is practical; however, in the aged case, it is necessary to manipulate these parameters to match the modeled data with experimental results. This is because the wettability becomes more oil-wet initially and surfactant leads to alteration in wettability.

- It has been suggested that while the effect of lowsalinity water as a single EOR method is very dependent on the initial wetting condition, the combination with surfactant has a significant effect on surfactant phase behavior to reach ultra-low IFT in high-salinity reservoirs. Since the formation brine salinity level of many reservoirs is more than the optimum salinity of almost all the industrial surfactants, combining the surfactant with low-salinity water gives better oil recovery.

- The combination of surfactant and low-salinity water does not always improve oil recovery. To obtain the highest amount of overall oil recovery, a careful design is needed and surfactant phase behavior parameters such as optimum salinity, $C_{\mathrm{SEU}}, C_{\mathrm{SEL}}$, and initial formation brine salinity should be taken into consideration.

- In this reservoir model, secondary recovery is more efficient than tertiary recovery mode because it leads to earlier oil recovery.

Acknowledgements The authors would like to acknowledge financial support for this research from the Research Council of Norway, and Institute for Energy Technology (IFE) AS (http://www.ife.no). We also would like to acknowledge the resources and staff of the Department of Petroleum Engineering and Applied Geophysics at the Norwegian University of Science and Technology.

Open Access This article is distributed under the terms of the Creative Commons Attribution 4.0 International License (http:// creativecommons.org/licenses/by/4.0/), which permits unrestricted use, distribution, and reproduction in any medium, provided you give appropriate credit to the original author(s) and the source, provide a link to the Creative Commons license, and indicate if changes were made. 


\section{References}

Abbasi Asl, Y., Pope, G. A., Delshad, M. (2010) Mechanistic modeling of chemical transport in naturally fractured oil reservoirs. Society of Petroleum Engineers. doi:10.2118/ 129661-MS

Al-Hadhrami HS, Blunt MJ (2000) Thermally induced wettability alteration to improve oil recovery in fractured reservoirs. society of petroleum engineers. doi:10.2118/59289-MS

Anderson WG (1986a) Wettability literature survey—part 1: Rock/Oil/ Brine interactions and the effects of core handling on wettability. Society of Petroleum Engineers. doi:10.2118/13932-PA

Anderson W (1986b) Wettability literature survey—part 2: wettability measurement. Society of Petroleum Engineers. doi:10.2118/ 13933-PA

Asakawa K (2005). A generalized analysis of partitioning interwell tracer tests. PhD dissertation, The University of Texas at Austin

Bourrel M, Schechter RS (1988) Microemulsions and related systems. Marcel Dekker Inc., NY

Buckley JS, Takamura K, Morrow NR (1989) Influence of electrical surface charges on the wetting properties of crude oils. Society of Petroleum Engineers. doi:10.2118/16964-PA

Carale TR, Pham QT, Blankschtein D (1994) Salt effects on intramicellar interactions and micellization of nonionic surfactants in aqueous solutions. Langmuir 10(1):109-121

Cense AW, Berg S (2009). The viscous-capillary paradox in 2-phase flow in porous media. SCA, Noordwijk aan Zee, The Netherlands $27-30$ Sep

Chiou CS, Chang HL (1978). Preflood design for chemical floodinga study on ion-exchange/dispersion process in porous media. Paper 376, presented at AICHE 84th National Meeting, Atlanta, GA, Feb 26-March 1

Cooke CE (1971). Method of determining fluid saturations in reservoirs. US. patent no. 3590923

Danckwerts PV (1953) Continuous flow systems, distribution of residence times. Chem Eng Sci 2(1):1-18

Deans HA (1978) Using chemical tracers to measure fractional flow and saturation in-situ. Society of Petroleum Engineers. doi:10. 2118/7076-MS

Delshad M, Delshad M, Bhuyan D, Pope GA, Lake LW (1986) Effect of capillary number on the residual saturation of a three-phase micellar solution. Society of Petroleum Engineers. doi:10.2118/ 14911-MS

Du Prey EL (1978) Gravity and capillarity effects on imbibition in porous media. Society of Petroleum Engineers. doi:10.2118/ 6192-PA

Dubey ST, Doe PH (1993) Base number and wetting properties of crude oils. Society of Petroleum Engineers. doi:10.2118/22598PA

Dwarakanath V, Chaturvedi T, Jackson A, Malik T, Siregar AA, Zhao $\mathrm{P}$ (2008) Using co-solvents to provide gradients and improve oil recovery during chemical flooding in a light oil reservoir. Society of Petroleum Engineers. doi:10.2118/113965-MS

Filoco PR, Sharma MM (1998) Effect of brine salinity and crude oil properties on relative permeabilities and residual saturations. Society of Petroleum Engineers. doi:10.2118/49320-MS

Flaaten A, Nguyen QP, Pope GA, Zhang J (2009) A systematic laboratory approach to low-cost, high-performance chemical flooding. Society of Petroleum Engineers. doi:10.2118/113469-PA

Gale WW, Sandvik EI (1973) Tertiary surfactant flooding: petroleum sulfonate composition-efficacy studies. Society of Petroleum Engineers. doi:10.2118/3804-PA

Gupta SP, Trushenski SP (1979) Micellar flooding - compositional effects on oil displacement. Society of Petroleum Engineers. doi:10.2118/7063-PA
Healy RN, Reed RL (1974) Physsicochemical aspects of microemulsion flooding. Society of Petroleum Engineers. doi:10.2118/ 4583-PA

Healy RN, Reed RL (1977) Immiscible microemulsion flooding. Society of Petroleum Engineers. doi:10.2118/5817-PA

Healy RN, Reed RL, Stenmark DG (1976). Multiphase microemulsion systems. Society of Petroleum Engineers. doi:10.2118/ 5565-PA

Hill HJ, Helfferich FG, Lake LW, Reisberg J, Pope GA (1977) Cation exchange and chemical flooding. Society of Petroleum Engineers. doi:10.2118/6642-PA

Hirasaki GJ (1981) Application of the theory of multicomponent, multiphase displacement to three-component, two-phase surfactant flooding. Society of Petroleum Engineers. doi:10.2118/8373-PA

Hirasaki G (1982) Ion exchange with clays in the presence of surfactant. Society of Petroleum Engineers. doi:10.2118/9279PA

Hirasaki GJ, Miller CA, Pope GA, Jackson RE (2004) Surfactant based enhanced oil recovery and foam mobility control. DOE annual technical report. Contract DE-FC26-03NT15406

Hirasaki GJ, Lawson JB (1986) An electrostatic approach to the association of sodium and calcium with surfactant micelles. Society of Petroleum Engineers. doi:10.2118/10921-PA

Hirasaki GJ, van Domselaar HR, Nelson RC (1983) Evaluation of the salinity gradient concept in surfactant flooding. Society of Petroleum Engineers. doi:10.2118/8825-PA

Hirasaki G, Miller CA, Puerto M (2011) Recent advances in surfactant eor. Society of Petroleum Engineers. doi:10.2118/ 115386-PA

Huh C (1979) Interfacial tension and solubilization ability of a microemulsion phase that coexists with oil and brine. J Colloid Interface Sci 71:408-428

Jin M (1995) A study of nonaqueous phase liquid characterization and surfactant remediation. Ph.D. dissertation, The University of Texas at Austin

Kamath J, Meyer RF, Nakagawa FM (2001) Understanding waterflood residual oil saturation of four carbonate rock types. Society of Petroleum Engineers. doi:10.2118/71505-MS

Karnanda W, Benzagouta MS, AlQuraishi A, Amro MM (2012). Effect of temperature, salinity, and surfactant concentration on IFT for surfactant flooding optimization. Saudi Society for Geosciences, pp 3535-3544

Khaledialidusti R, Kleppe J, Enayatpour S (2014) Evaluation and comparison of available tracer methods for determining residual oil saturation and developing an innovative single well tracer technique: dual salinity tracer. In: International petroleum technology conference. doi:10.2523/17990-MS

Khaledialidusti R, Kleppe J, Skrettingland K (2015a) Numerical interpretation of single well chemical tracer (SWCT) tests to determine residual oil saturation in snorre reservoir. Society of Petroleum Engineers. doi:10.2118/174378-MS

Khaledialidusti R, Enayatpour S, Badham SJ, Carlisle CT, Kleppe J (2015b) An innovative technique for determining residual and current oil saturations using a combination of Log-Inject-Log and SWCT test methods: LIL-SWCT. J Pet Sci Eng 135:618-625. doi:10.1016/j.petrol.2015.10.023

Khaledialidusti R, Kleppe J, Enayatpour S (2015c) Mechanistic modeling of alkaline/surfactant/polymer floods based on the geochemical reactions for snorre reservoir. Society of Petroleum Engineers. doi:10.2118/175655-MS

Lager A, Webb KJ, Black CJJ, Singleton M, Sorbie KS (2008) Low salinity oil recovery-an experimental investigation1. Society of Petrophysicists and Well-Log Analysts

Lake LW (1989) Enhanced oil recovery. Prentice-Hall, Englewod Cliff 
Levitt D, Jackson A, Heinson C, Britton LN, Malik T, Dwarakanath V, Pope GA (2009) Identification and evaluation of highperformance EOR surfactants. Society of Petroleum Engineers. doi:10.2118/100089-PA

Maerker JM, Gale WW (1992) Surfactant flood process design for loudon. Society of Petroleum Engineers. doi:10.2118/20218-PA

Menezes JL, Yan J, Sharma MM (1989) The mechanism of wettability alteration due to surfactants in oil-based muds. Society of Petroleum Engineers. doi:10.2118/18460-MS

Nelson RC (1981) Further studies on phase relations in chemical flooding. In: Shah DO (ed) Surface phenomena in enhanced oil recovery. Plenum Publishing, New York, pp 73-104

Nelson RC, Pope GA (1978) Phase relationships in chemical flooding. Society of Petroleum Engineers. doi:10.2118/6773-PA

Pope GA, Lake LW, Helfferich FG (1978) Cation exchange in chemical flooding: part 1-basic theory without dispersion. Society of Petroleum Engineers. doi:10.2118/6771-PA

Robertson EP (2007) Low-salinity waterflooding to improve oil recovery-historical field evidence. Society of Petroleum Engineers. doi:10.2118/109965-MS

Santos FKG, Neto ELB, Moura MCPA, Dantas TNC, Neto AAD (2009) Molecular behavior of ionic and nonionic surfactants in saline medium. Colloids Surf A Physicochem Eng Asp 333(1-3):156-162. doi:10.1016/j.colsurfa.2008.09.040

Shah DO, Schechter RS (1977) Improved oil recovery by surfactant and polymer flooding. Academic Press, New York

Stegemeier GL (1977) Mechanism of entrapment and mobilization of oil in porous media. In: Shah DO, Schechter RS (eds) Improved oil recovery by surfactant and polymer flooding. Academic Press, New York
Taber JJ (1969) Dynamic and static forces required to remove a discontinuous oil phase from porous media containing both oil and water. Society of Petroleum Engineers. doi:10.2118/2098-PA

Tang J (2005) Extended brigham model for residual oil saturation measurement by partitioning tracer tests. Society of Petroleum Engineers. doi:10.2118/84874-PA

Teklu TW, Brown JS, Kazemi H, Graves RM, AlSumaiti AM (2013) A critical literature review of laboratory and field scale determination of residual oil saturation. Society of Petroleum Engineers. doi: $10.2118 / 164483-\mathrm{MS}$

Tie H, Morrow NR (2005) Low-flood-rate residual saturations in carbonate rocks. In: International petroleum technology conference. doi:10.2523/10470-MS

Tomich JF, Dalton RL, Deans HA, Shallenberger LK (1973) Singlewell tracer method to measure residual oil saturation. Society of Petroleum Engineers. doi:10.2118/3792-PA

Treiber LE, Owens WW (1972) A laboratory evaluation of the wettability of fifty oil-producing reservoirs. Society of Petroleum Engineers. doi: 10.2118/3526-PA

Webb KJ, Black JJ, Al-Jeel H (2004). Low salinity oil recovery-the role of Geosciencientists and Engineers. Presented at 13th European symposium on improved oil recovery

Winsor PA (1954) Solvent properties of amphiphilic compound. Butterworth, London, p 68

Zhang D, Liu S, Yan W, Puerto M, Hirasaki GJ, Miller CA (2006) Favorable attributes of alkali-surfactant-polymer flooding. Society of Petroleum Engineers. doi:10.2118/99744-MS

Zhang Y, Xie X, Morrow NR (2007) Waterflood performance by injection of brine with different salinity for reservoir cores. Society of Petroleum Engineers. doi:10.2118/109849-MS 